Do all chlorophyll fluorescence emission wavelengths capture the spring recovery of photosynthesis in boreal evergreen foliage?

\title{
Zhang, Chao
}

2019-12

Zhang , C , Atherton, J , Penuelas, J Filella , I , Kolari , P , Aalto , J , Ruhanen , H , Back , J \& Porcar-Castell , A 2019 , ' Do all chlorophyll fluorescence emission wavelengths capture the spring recovery of photosynthesis in boreal evergreen foliage? ' , Plant, Cell and Environment, vol. 42 , no. 12 , pp. 3264-3279 . https://doi.org/10.1111/pce.13620

http://hdl.handle.net/10138/321552

https://doi.org/10.1111/pce.13620

unspecified

acceptedVersion

Downloaded from Helda, University of Helsinki institutional repository.

This is an electronic reprint of the original article.

This reprint may differ from the original in pagination and typographic detail.

Please cite the original version. 
Zhang Chao (Orcid ID: 0000-0001-7327-9477)

Bäck Jaana (Orcid ID: 0000-0002-6107-667X)

\section{Do all chlorophyll fluorescence emission wavelengths capture the spring} recovery of photosynthesis in boreal evergreen foliage?

Running title: Spectral fluorescence in evergreens

Chao Zhang ${ }^{1,2,3, ~ *}$, Jon Atherton ${ }^{1}$, Josep Peñuelas ${ }^{2,3}$, lolanda Filella ${ }^{2,3}$, Pasi Kolari ${ }^{4}$, Juho Aalto ${ }^{4,5}$, Hanna Ruhanen ${ }^{6}$, Jaana Bäck ${ }^{7}$, Albert Porcar-Castell1, ${ }^{*}$

${ }^{1}$ Optics of Photosynthesis Laboratory, Institute for Atmospheric and Earth System Research (INAR)/Forest Sciences/Viikki Plant Science Centre, Faculty of Agriculture and Forestry, University of Helsinki, PO Box 27, 00014 Helsinki, Finland.

${ }^{2}$ CREAF, Center for Ecological Research and Forestry Applications, Bellaterra 08193, Catalonia, Spain.

${ }^{3}$ CSIC, Global Ecology Unit CREAF-CSIC-UAB, Cerdanyola del Vallès 08193, Catalonia, Spain

${ }^{4}$ Department of Physics, University of Helsinki, PO Box 64, 00014 Helsinki, Finland.

5SMEAR II Station, University of Helsinki, Hyytiäläntie 124, Korkeakoski 35500, Finland

This article has been accepted for publication and undergone full peer review but has not been through the copyediting, typesetting, pagination and proofreading process which may lead to differences between this version and the Version of Record. Please cite this article as doi: $10.1111 /$ pce. 13620 
${ }^{6}$ Natural Resources Institute Finland (Luke), Natural Resources and Bioproduction, Suonenjoki Unit, Juntintie 154, 77600 Suonenjoki, Finland.

${ }^{7}$ Department of Forest Sciences, University of Helsinki, PO Box 27, 00014 Helsinki, Finland.

*Corresponding authors: Chao Zhang, chao.x.zhang@helsinki.fi; Albert Porcar-

Castell, joan.porcar@helsinki.fi

\section{Abstract}

Chlorophyll a fluorescence (ChIF) is closely related to photosynthesis and can be measured remotely using multiple spectral features as solar-induced fluorescence (SIF). In boreal regions, SIF shows particular promise as an indicator of photosynthesis; in part because of the limited variation of seasonal light absorption in these ecosystems. Seasonal spectral changes in ChIF could yield new information on processes such as sustained non-photochemical quenching (NPQs), but also disrupt the relationship between SIF and photosynthesis. We followed ChIF, functional and biochemical properties of Pinus sylvestris needles during the photosynthetic spring recovery period to answer; (1) how ChIF spectra change over seasonal timescales? (2) How pigments, NPQs and total PAR absorption drive changes of ChIF spectra? (3) Do all ChIF wavelengths track photosynthetic seasonality? We found seasonal ChIF variation in the red and far-red wavelengths, which was strongly correlated with NPQs, carotenoid content and photosynthesis (enhanced in the red), but not with PAR absorption. Furthermore, a rapid decrease in red/far-red ChIF ratio occurred in response to a cold spell, potentially relating to the structural reorganization of the photosystems. We conclude that all current SIF retrieval features can track seasonal 
photosynthetic dynamics in boreal evergreens, but the full SIF spectra provides additional insight.

Key words: chlorophyll a fluorescence spectra, evergreen vegetation, $F_{690}$, F 740, leaf PAR absorption, Pinus sylvestris, PSI fluorescence, fluorescence ratio, sustained nonphotochemical quenching (NPQs)

\section{Summary statement}

Chlorophyll fluorescence, a signal used to track photosynthesis at multiple scales, is distributed across a range of wavelengths. We followed chlorophyll fluorescence spectra during the photosynthetic spring recovery period for Pinus sy/vestris. We found strong correlations between photosynthesis and fluorescence in both red and far-red emission wavelengths, and also minor changes in spectral shape related to short-term environmental stimuli.

\section{Introduction}

Chlorophyll a fluorescence (ChIF) of leaves, thylakoids and photosystems has been extensively used to study the organization, functioning, and acclimation of the photosynthetic light harvesting apparatus (Govindjee 1995; Baker 2008; Murchie \& Lawson 2013; Porcar-Castell et al. 2014). ChIF can now be measured within discrete wavelengths from plant canopies, forest stands, and whole ecosystems with instrumentation on towers, drones, aircraft and satellites (Zarco-Tejada, Catalina, González \& Martín 2013; Porcar-Castell et al. 2015; Rascher et al. 2015; Joiner, Yoshida, Guanter \& Middleton 2016; Sun et al. 2017; Parazoo et al. 2018). Widely addressed as solar-induced fluorescence (SIF) by the remote sensing community, SIF opens up the study of photosynthesis at unprecedented scales (Frankenberg et al. 2011, 2014; Parazoo et al. 2014; Thum et al. 2017; Sun et al. 2018; Zhang, Guanter, Joiner, Song \& Guan 2018; Zuromski et al. 2018). This capacity could not only serve to improve the current accuracy of global carbon budgets (Damm et al. 2015; Quéré 
et al. 2018; Smith et al. 2018) but yield new understanding on the responses and feedbacks between terrestrial ecosystems and the environment, both critical milestones for the implementation of climate change mitigation and adaptation strategies (Smith et al. 2014; IPCC-SR15 2018).

Despite the mounting evidence of the strong link between SIF and gross primary productivity (GPP) accumulating from ground, airborne and satellite platforms (Guanter et al. 2014; Zarco-Tejada, González-Dugo \& Fereres 2016; Migliavacca et al. 2017; Sun et al. 2017; Parazoo et al. 2018; Zuromski et al. 2018; Magney et al. 2019a), the physical and biological mechanisms that underpin the relationship and the potential wavelength-dependent information content in the SIF signal remain unclear (Porcar-Castell et al. 2014; Verrelst et al. 2016; Wieneke et al. 2018; Yang et al. 2018). This lack of understanding, is particularly acute for evergreen foliage, where the seasonal link between SIF and GPP involves processes other than changes in absorbed photosynthetically active radiation(APAR) which could decouple and add wavelength dependencies to the relationship between SIF and GPP.

In contrast to pulse-amplitude-modulation (PAM) ChIF measurements which integrate ChIF over a broad range of wavelengths, SIF is retrieved within narrow and discrete spectral bands around the red and far-red ChIF emission peaks (atmospheric oxygen absorption bands or solar Fraunhofer lines) (Alonso et al. 2007; Meroni et al. 2009). Accordingly, because the shape of the leaf-level ChIF spectra is driven by a combination of physical, physiological and biochemical factors (Magney et al. 2019b), it can be expected that the seasonal relationship between SIF and GPP would depend on retrieval wavelength, especially in boreal evergreen vegetation undergoing remarkable adjustments during the season. 
A light use efficiency type model (Monteith 1972) becomes a convenient theoretical framework to introduce the physical and biological factors that couple (or decouple) SIF and GPP, and connect the leaf-level phenomenology to the spatial scale of remote sensing. The intensity of the SIF signal emitted from a leaf or a plant canopy at a given wavelength $(\lambda)$ can be expressed as a function of four factors: 1) the incoming PAR, 2) the fraction of that PAR absorbed by the leaf or canopy $(A), 3)$ the quantum yield of fluorescence with its associated emission wavelength $\left(\Phi_{F}(\lambda)\right)$, and 4) a wavelength dependent escape probability $\left(f_{\mathrm{esc}}(\lambda)\right)$ which accounts for the reabsorption of predominantly red ChIF photons by chlorophyll (Chl) molecules within the antenna, thylakoid, chloroplast, leaf or plant canopy (Buschmann 2007; Porcar-Castell et al. 2014; Romero, Cordon \& Lagorio 2018; Yang \& van der Tol 2018), as:

$$
\operatorname{SIF}(\lambda)=P A R \cdot A \cdot \Phi_{F}(\lambda) \cdot f_{\text {esc }}(\lambda)
$$

In similar terms, leaf or canopy level GPP can be expressed as:

$$
G P P=P A R \cdot A \cdot L U E
$$

where LUE corresponds to the photosynthetic light use efficiency in moles of $\mathrm{CO}_{2}$ assimilated moles per mole of absorbed PAR photons. By combining equations (note that $A$ and PAR cancel out), a simple theoretical relationship that links GPP to SIF can be obtained as:

$$
G P P=\frac{1}{f_{e s c}(\lambda)} \cdot \frac{L U E}{\Phi_{F}(\lambda)} \cdot \operatorname{SIF}(\lambda) \quad(\text { Eqn. 3) }
$$

In this equation, widely applied to the interpretation of remotely sensed SIF data (Guanter et al. 2014; van der Tol, Berry, Campbell \& Rascher 2014; Damm et al. 2015; Lee et al. 2015; Frankenberg \& Berry 2018), physical factors (e.g. structure-dependent ChIF reabsorption) are embedded in the $1 / f_{\text {esc }}(\lambda)$ term, and biological factors (e.g. 
architecture and physiological state of the light reactions, alternative energy sinks, cyclic electron transport, photorespiration) are embedded in the $L U E / \Phi_{F}(\lambda)$ term. Clearly, any seasonal changes in the strength of the factors above can potentially couple and decouple SIF and GPP (Porcar-Castell et al. 2014). In addition, any seasonal changes in the leaf-level wavelength properties of $f_{\mathrm{esc}}(\lambda)$ and $\Phi_{\mathrm{F}}(\lambda)$ can add wavelength dependencies to the link between $\operatorname{SIF}(\lambda)$ and GPP, something that remains to be characterized.

Seasonal changes in leaf Chl content, although usually modest in boreal evergreens (Öquist \& Huner 2003; Ensminger et al. 2004; Porcar-Castell et al. 2008a), affect light absorption, and also $f_{\text {esc }}(\lambda)$ via ChIF reabsorption (Buschmann 2007). Similarly, structural changes at the level of chloroplast and thylakoid membrane, e.g. thylakoid grana unstacking and aggregation of $\mathrm{Chl}$ binding light harvesting complexes in overwintering evergreens (Öquist, Chow \& Anderson 1992; Ruban, Johnson \& Duffy 2012; Verhoeven 2014; Demmig-Adams, Muller, Stewart, Cohu \& Adams 2015; Ruban 2016) could also contribute to the modulation of $f_{\mathrm{esc}}(\lambda)$ potentially affecting the spectral properties of SIF and its seasonal correlation to GPP.

$\Phi_{F}(\lambda)$ is composed of at least two components: a highly dynamic component which responds to photochemical (PQ) and non-photochemical (NPQ) quenching of excitation energy in photosystem II (PSII) and that fluoresces in the red and far-red regions (Franck, Juneau \& Popovic 2002; Palombi et al. 2011), and a component from photosystem I (PSI) assumed to remain stationary over the short term (Genty, Wonders \& Baker 1990; Palombi et al. 2011; Pfündel, Klughammer, Meister \& Cerovic 2013) that fluoresces predominantly in the near-infrared. Accordingly, if seasonal dynamics in sustained NPQ (NPQs) (Ottander, Campbell \& Öquist 1995; Öquist \& Huner 2003; Verhoeven 2014) quenched only the ChIF components from PSII, one 
would expect NPQs to affect the spectral properties of $\Phi_{F}(\lambda)$. Similarly, differences in the patterns of seasonal photoinhibition of PSII (Ensminger et al. 2004; Murata, Takahashi, Nishiyama \& Allakhverdiev 2007) and PSI reaction centres (Sonoike 2011; Huang, Yang, Hu \& Zhang 2016) could also affect the ChIF spectra and its spectral dependency with photosynthesis.

In summary, although a strong seasonal coupling between PAM ChIF and photosynthesis has been widely reported for evergreen foliage (e.g. Ottander \& Öquist 1991; Ensminger et al. 2004; Zarter, Demmig-Adams, Ebbert, Adamska \& Adams 2006b; Soukupová et al. 2008; Kolari et al. 2014; Springer, Wang \& Gamon 2017), the spectral dependency of the relationship remains unresolved.

The objective of the study was to characterize the seasonal variation of ChIF spectra for boreal evergreen Scots pine needles during the spring recovery of photosynthesis. Hence, we investigated if red and far-red wavelengths of ChIF were equally positioned to capture the spring recovery of photosynthesis. To do so we combined long-term and continuous in situ measurements of gas exchange, and PAM ChIF with repeated measurements of foliar pigment content, leaf total PAR absorption and spectral ChIF, spanning the full dynamic range of variation in photosynthetic capacity of Scots pine needles: from deeply downregulated foliage during winter, to fully functional foliage during peak growing season in summer.

\section{Materials and methods}

Study site and field sampling protocol

Measurements were conducted at Hyytiälä/SMEAR-II (Station for Measuring Forest Ecosystem-Atmosphere Relations) in Southern Finland $\left(61^{\circ} 51^{\prime} \mathrm{N}, 24^{\circ} 17^{\prime} \mathrm{E}, 181 \mathrm{~m}\right.$ a. s. 
I.) (Hari \& Kulmala 2005), in a 52-year old Scots pine (Pinus sylvestris L.) stand with a dominant height of c. $18 \mathrm{~m}$. The study period (24 ${ }^{\text {th }}$ February $-20^{\text {th }}$ July 2015) encompassed three biological seasons: end of winter (full dormant state), spring, and first half of summer (peak growing season).

The study combined continuous in situ measurements of micrometeorological variables, $\mathrm{CO}_{2}$ exchange and PAM ChlF across four different trees $(\mathrm{N}=4)$, with repeated point measurements of steady-state spectral ChIF at room temperature and pigment analysis across five trees (previous four plus one, $\mathrm{N}=5$ ). Spectral ChIF was purposefully measured under standardized PAR so that it could serve as a proxy of $\Phi_{F}(\lambda)$ in Eqns 1 and 3, (i.e. APAR assumed constant). To avoid changing the needle cohort in the middle of the experiment, all measurements were conducted in the newest cohort of needles available at the start of the study period (developed in summer 2014). To avoid defoliation effects, several branches from the four topmost whorls were selected per tree and used for the repeated sampling of needles. Needles were sampled always before 10AM. Overall, the study included a total of 19 measuring points in addition to the continuous measurements (Fig. 1).

Continuous measurements of micrometeorological data and shoot $\mathrm{CO}_{2}$ exchange

Air temperature $\left({ }^{\circ} \mathrm{C}\right)\left(\mathrm{Pt} 100\right.$ sensor) and PAR $\left(\mu \mathrm{mol} \mathrm{m} \mathrm{m}^{-2} \mathrm{~s}^{-1}\right)(\mathrm{Li}-190 \mathrm{SZ}$, Li-Cor Inc., Lincoln, NE, USA) were measured right above the forest at $1 \mathrm{~min}$ intervals from sensors placed in a tall mast. The $\mathrm{CO}_{2}$ exchange of pine shoots was measured in top canopy shoots 30-60 times per day using a system of automated dynamic chambers coupled to an infrared gas analyzer (Li-840, Li-Cor Inc., Lincoln, NE, USA) (see e.g. Aalto et al. 2014 for further details). Chambers remained open most of the time 
exposing the studied shoots to ambient conditions and closed only during measurement. Fluxes were estimated from the change in $\mathrm{CO}_{2}$ concentration during the first $40 \mathrm{~s}$ upon chamber closure (Kolari et al. 2012). Shoots with fully developed needles from 2014 were debudded prior to chamber installation to prevent new growth during the study period and for practical reasons. Total needle area inside the chamber was measured at the end of the study and used to calculate fluxes. A total of two to four chambers $(\mathrm{N}=2-4)$ were used during the study period from February 24th to July 20th in 2015 (Fig. S1a).

Direct comparison of noon LUE from chamber data (moles $\mathrm{CO}_{2}$ assimilated /moles PAR absorbed) can be problematic in boreal conditions due to low PAR levels during the winter months. Accordingly, we decided to use here a simple model of photosynthesis (the optimal stomatal control model) (Hari, Mäkelä, Korpilahti \& Holmberg 1986; Kolari, Lappalainen, Hänninen \& Hari 2007) that allows robust estimation of photosynthetic parameters under ambient $\mathrm{CO}_{2}$ concentrations, low light and low temperatures (Kolari et al. 2014). Two key photosynthetic parameters were estimated in a 3-day time window to capture the seasonal development in LUE; (1) $\alpha$ ( $\mu \mathrm{mol} \mathrm{CO}_{2} / \mu \mathrm{mol}$ PAR), the slope of a linear function fitted to the photosynthetic light response with low incident PAR $\left(<300 \mu \mathrm{mol} \mathrm{m} \mathrm{m}^{-2} \mathrm{~s}^{-1}\right)$ before noon (Fig. S1b; Kolari et al. 2014). Under constant leaf PAR absorption (Fig. S2), this parameter can be considered a measure of maximum photosynthetic LUE under low light. In addition, and since our spectral ChIF measurements were not conducted under low light, we also estimated (2) $\beta$ ( $\left.\mathrm{m} \mathrm{s}^{-1}\right)$, the maximum rate of light-saturated photosynthesis per unit inter-cellular $\mathrm{CO}_{2}$ concentration (Fig. S1c). This parameter can be considered a measure of light-saturated photosynthesis at optimal temperature, low vapour pressure deficit and ambient $\mathrm{CO}_{2}$ concentration. 
We normalized $\alpha$ and $\beta$ parameters to their mean values between May 3rd and 23rd (see Fig. S1d,e). This is a common procedure in time-series analysis and serves to minimize the impact of systematic variability and emphasize the seasonal patterns in the data, which was our goal. The normalization period was selected in May as that was the time when all four chambers were simultaneously recording and the foliage was already photosynthetically active. Normalized unit-less values were then converted back to the original units by multiplying the normalized values by the respective means across all four chambers. The parameters $\alpha$ and $\beta$ are used hereinafter as a measure of the seasonal spring recovery of photosynthesis.

Continuous measurements of PAM ChIF in situ

A Monitoring PAM system (MONI-PAM, Walz GmbH, and Germany) (Porcar-Castell, Pfündel, Korhonen \& Juurola 2008b; Porcar-Castell 2011), equipped with 4 independent PAM fluorometers, was used to record the instantaneous fluorescence yield $\left(F^{\prime}\right)$, the maximal fluorescence yield $\left(F^{\prime} M\right)$, incoming PAR, and temperature every 30 minutes. Night $F^{\prime}$ and $F^{\prime} M$ were assumed to correspond to minimal $\left(F_{0}\right)$ and maximal $\left(F_{M}\right)$ fluorescence and used to derive daily maximum quantum yield of PSII, Fv/FMafter Kitajima \& Butler (1975), and to calculate quenching parameters NPQs and PQs after Porcar-castell (2011) as: NPQs $=F_{M R} / F_{M}-1$ and $P Q_{S}=F_{M R} / F_{O}-F_{M R} / F_{M}$, where $F_{M R}$ is the summer night reference obtained for those particular needles in the absence of NPQs. A decrease in PQs relative to summer levels was here interpreted in terms of photoinhibition of reaction centres (Porcar-Castell 2011). Finally, seasonal changes in PAM based fluorescence yield $\left(\Phi_{\mathrm{F}}\right)$ were estimated as $\Phi_{\mathrm{F}}=0.1 \mathrm{~F}_{\mathrm{o}} / \mathrm{F}_{\mathrm{MR}}$ (Porcar-castell 2011, note the unfortunate typo in Eqn. 24 therein where $F^{\prime} M$ should be $F_{M R}$ ), which is 
based on the assumption of a maximum fluorescence yield of $10 \%$ for PSIl particles at the $\mathrm{F}_{M}$ state (Barber, Malkin \& Telfer 1989). The four fluorometers were installed in top canopy branches pointing south.

\section{Validation of ChIF measurements}

For practical reasons, this study compared ChIF spectra of cut needles measured under standard conditions and at room temperature, with photosynthetic parameters $\left(\alpha, \beta, F v / F_{M}, N P Q s\right.$ and PQs, obtained from the field instrumentation. Accordingly, we wanted to test that our measurements at room temperature correctly represented the same physiological state as measurements carried out in the field. In addition, we wanted to ensure that our MONI-PAM system (which consistently supplied 48 light pulses per day to the same needles throughout the study period) was not introducing any long-term artefact. We used a Hansatech fluorometer (FMS-2, Hansatech Instruments Ltd., Kings Lynn, Norfolk, UK) to measure $\mathrm{Fv}_{\mathrm{V}} \mathrm{F}_{\mathrm{M}}$ both in the field and under standardized conditions indoors. During each sampling point, we placed a total of 25 dark-acclimation clips, distributed across the five study trees, and dark acclimated for at least 1 hour prior to measuring Fv/FM. The same measurements were subsequently repeated at room temperature using collected needles instead. As expected, Fv/FM obtained from the FMS-2 in the field was highly correlated with estimates from the MONI-PAM system ( $r=0.97, P<0.0001)$ (Fig. S3), denoting that the MONI-PAM system did not introduce any bias into the observed seasonal patterns. The small discrepancy between slopes is very likely due to differences in the colour of the measuring light as well as the ChIF detection range between instruments. Similarly, Fv/FM measurements obtained with the FMS-2 fluorometer in field were found to be strongly correlated with those of detached needles at room temperature $(r=0.94, P<0.0001)$ (Fig. S3), 
suggesting that room temperature measurements did not introduce any major bias into the observed seasonal patterns in spectral ChIF.

\section{Estimation of foliar pigment content}

During each sampling point, five pairs of needles were randomly detached per each tree using the pre-selected top branches and needle cohort. Needles were sampled into cryotubes, immediately frozen at liquid nitrogen temperature using a portable dewar (CX-100, Taylor Wharton International LLC, Minnetonka, MN), and subsequently stored at $-80{ }^{\circ} \mathrm{C}$ until extraction. Pigment analysis were conducted following Wellburn (1994) with dimethyl sulfoxide (DMSO; VWR Chemicals, 23500.322) as solvent. Frozen samples $(75-100 \mathrm{mg})$ were first homogenized for 2 minutes at $30 \mathrm{~Hz}$, using a bead mill (TissueLyser II Qiagen, Germany), stainless steel beads $(4 \mathrm{~mm})$ and microtubules $(2 \mathrm{~mL})$. Subsequently, $1.8 \mathrm{~mL}$ of DMSO was added to the homogenate and resuspended again at $30 \mathrm{~Hz}$ for 1 minute. Pigments were extracted in oven at $40{ }^{\circ} \mathrm{C}$ for 4 hours. Extracts were then centrifuged at $25000 \mathrm{~g}$ for 5 minutes. Light absorption was measured at $649.1 \mathrm{~nm}, 665.1 \mathrm{~nm}$ and $480.0 \mathrm{~nm}$, with a spectrophotometer (Shimadzu UV- 2401 PC), and subsequently used for estimation of Chl a, Chl b and total carotenoids (Wellburn 1994).

\section{Measurements of leaf absorption}

Needle PAR absorption $\left(A_{T(P A R)}\right)$ was measured 8 times during the study period $(\mathrm{N}=5$ biological replicates). We used the same spectrometer and LED light source described above connected to a 6 inch diameter integrating sphere (AdaptaSphere, LabSphere Inc, New Hampshire, UK), and applied the black spray method (Olascoaga, Mac

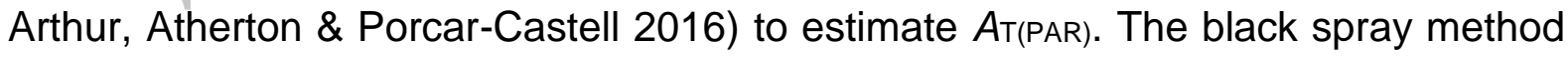


was inspired by earlier within-sphere measurements (Öquist, Hällgren \& Brunes 1978; Idle \& Proctor 1983) and purposefully developed to measure absorption in leaves with complex geometry, like needles, because it does not require mounting needles in the port of the integrating sphere and therefore there are no gap effects. Instead, samples are placed inside the sphere and hung from a white thread across the central plane (see illustrations in Olascoaga et al. 2016 for details). Prior to measurements, 5-6 needle pairs were separated and the resulting 10-12 needles sewed with a white thread and spaced at least $1 \mathrm{~cm}$. The method consisted of three separate spectral measurements inside the sphere: 1) white thread alone (reference zero absorption, Iw), 2) white thread with needles (sample absorption, Is), and 3) white thread with needles painted with a black spray of known absorption (Black sample, IB). Conveniently, because the total surface area of the needles in steps 2) and 3) can be assumed to remain constant, this parameter cancels out and there is no need to estimate it. Total PAR absorption can then be computed by combining these three measurements with the known absorption of the black spray (ABLACK), as:

$$
A_{\mathrm{T}}=\frac{\left(I_{\mathrm{W}}-I_{\mathrm{S}}\right) I_{\mathrm{B}} A_{\mathrm{BLACK}}}{\left(I_{\mathrm{W}}-I_{\mathrm{B}}\right) I_{\mathrm{S}}} \quad \text { Eqn. } 4
$$

The mean value of $A_{T}$ between 400 and $700 \mathrm{~nm}$ was here used as an estimate of $A_{\text {T(PAR). }}$

Room temperature measurements of leaf spectral ChIF

Leaf spectral $\operatorname{ChIF}\left(F_{\lambda}\right.$, in $\left.\mathrm{mW} \mathrm{m}^{-2} \mathrm{sr}^{-1} \mathrm{~nm}^{-1}\right)$ was measured at room temperature using a FluoWat Clip (Image Processing Laboratory, University of Valencia, Spain) (Van Wittenberghe, Alonso, Verrelst, Moreno \& Samson 2015) coupled with a powerful white LED (MJ-858, Magicshine, UK) and a radiometrically calibrated visible-near- 
infrared spectrometer (FieldSpec, ASD-Panalytical, Boulder, CO). The spectrometer covers the spectral range between 325 and $1075 \mathrm{~nm}$ at a sampling interval of $1 \mathrm{~nm}$ and with a FWHM of $3.5 \mathrm{~nm}$. The FluoWat clip has an optical window for input illumination (incidence angle of $45^{\circ}$ ) and a small aperture (at nadir view) to connect the optical fiber. The fiber field of view is $25^{\circ}$ and the distance to sample is $1 \mathrm{~cm}$, yielding an approximately circular target area of $0.22 \mathrm{~cm}$ radius. To obtain spectral ChIF, a 650 nm short-pass filter (Edmund Optics Ltd, UK, OD=4) was used to exclude $99.99 \%$ of radiation above $650 \mathrm{~nm}$. The LED source supplies a PAR of c. $1200 \mu \mathrm{mol}$ at the leaf surface as estimated with a PAR sensor (Licor LI150-A, Li-Cor Inc., Lincoln, NE, USA).

Needles were carefully arranged alongside each other to minimize the gap fraction and fixed with transparent tape to conform a needle mat (see Fig. 1). Rajewicz, Atherton, Alonso \& Porcar-Castell (2019) recently compared the ChIF spectra of needles with different arrangements, and concluded that despite the fact that needle mats could slightly enhance reabsorption, they provided a higher replicability and reproducibility and were therefore a good solution to track temporal changes in spectral properties.

Needle mats were dark adapted at $10{ }^{\circ} \mathrm{C}$ for 1 hour and kept in the dark until measurements started in the FluoWat clip. After conducting a dark current measurement, the needle mat was placed in the FluoWat clip, recording was started, and an opaque aluminium foil placed between the light source and the FluoWat clip rapidly removed. Variations of spectral ChIF were recorded during two minutes at an integration time of $136 \mathrm{~ms}$. The last ten spectra were averaged and used to estimate steady-state ChIF between $650 \mathrm{~nm}$ and $850 \mathrm{~nm}\left(F_{\lambda}\right)$. Averaged spectra were further smoothed using a Savitzky-Golay filter (order=2, averaging interval=15) and cut to a 
range of $660-780 \mathrm{~nm}$ where the signal was strongest. The resulting fluorescence spectra was used to estimate red $\left(\mathrm{F}_{690}\right)$ and far-red $\mathrm{ChIF}\left(\mathrm{F}_{740}\right)$ and used to calculate an integrated steady-state ChIF between 660 and $780 \mathrm{~nm}\left(\int_{660}^{780} F d \lambda\right)$ for correspondence with the broadband PAM fluorescence parameter, $\Phi_{F}$.

\section{Statistical analyses}

Mean values of four (gas exchange and Monitoring PAM fluorescence) or five (all other data) trees were used to conduct statistical analysis. Linear regression models and simple Pearson's correlation analyses were used to assess relationships between variables. All the analyses were conducted with $\mathrm{R}$ version 3.2.2 ( $\mathrm{R}$ Core Development Team, 2015) and MATLAB version R2014a (MathWorks Inc. 2014).

Principal Component Analysis (PCA) was used to quantitatively assess the relative role of different components of variation in the spectral ChIF dataset. In particular, we wanted to quantify how much of the seasonal variation in spectral ChIF during the spring recovery of photosynthesis was related to principal components associated with changes in the intensity and how much was related to principal components associated with changes in the shape. The R function 'prcomp' in the default mode ('prcomp' arguments; scale $=$ FALSE and center $=$ TRUE) was used to run a PCA on time series of the ChIF data-set. The analysis was focused on the $660-780 \mathrm{~nm}$ emission region to reduce impact of low signal-to-noise at wavelength limits. 


\section{Results}

Seasonal changes in micrometeorological variables and photosynthetic parameters

Both temperature and PAR followed the typical annual pattern in boreal regions with PAR increasing faster and earlier than temperature (Fig. 2a). Daily mean temperatures in February $\left(-1.7^{\circ} \mathrm{C}\right)$ and March $\left(0.6^{\circ} \mathrm{C}\right)$ were higher by 6 and $4{ }^{\circ} \mathrm{C}$, respectively, compared to the average for the period 1981-2010 (Pirinen et al. 2012). Fortunately, a cold spell took place on March 22nd with a daily mean temperature of $-5.7^{\circ} \mathrm{C}$. On April 16th, a second cold spell took place with a mean temperature of $0.7^{\circ} \mathrm{C}$. These cold spells served to assess the responses of ChIF and photosynthetic parameters to a sudden decrease in temperature and were highlighted in figures reporting the time series.

Noon mean $\mathrm{CO}_{2}$ fluxes (Fig. 2b) registered a clear seasonal pattern gradually increasing from April to June. Both $\alpha$ (a measure of maximum LUE under low light) and $\beta$ (a measure of maximum photosynthetic rate) displayed similar seasonal patterns (Fig. 2c), gradually increasing from winter to summer. The effect of the cold spells on $\alpha$ and $\beta$ parameters could not be distinguished.

Changes in the $\mathrm{Fv} / \mathrm{FM}_{\mathrm{M}}$ and $\Phi_{\mathrm{F}}$ (Fig. 2d) measured in the field with the MONI-PAM system also tracked the development of the spring recovery of photosynthesis, rapidly decreasing in response to the two cold spells and gradually recovering from winter to summer. Over the full spring recovery, $\Phi_{F}$ varied approximately by a factor of 2 from its minimum in early April to its maximum in June and July. Variations in $\mathrm{Fv} / \mathrm{F}_{\mathrm{M}}$ were further decomposed into PQs and NPQs components (Fig. 2e,f). NPQs presented larger seasonal variation decreasing from about 5 at the beginning of the study period to zero during summer. In contrast, $P Q$ s increased from values of about 3 at the 
beginning of the study period to values of 4.5 during summer. Both NPQs and PQs consistently responded to both cold spells, increasing and decreasing, respectively.

\section{Seasonal changes in pigment content and leaf absorption}

No obvious seasonal patterns were observed in total Chl levels (Fig. 3a) although a slightly decreasing trend occurred during spring which reversed towards summer. This result was consistent with the time-series of total leaf PAR absorption ( $A_{T(\mathrm{PAR})}$, Fig. S2) which did not display any seasonal pattern either with values ranging from 0.81 to 0.85 . In contrast, seasonal changes were observed in Chl b (Fig. 3c), Chl a/b (Fig. 3d), carotenoid content (Fig. 3e) and Car/Chl ratios (Fig. 3f). During early spring, Chl a/b ratios were lower and carotenoid and $\mathrm{Car} / \mathrm{Chl}$ ratios higher than during summer. No clear effects of the cold spells were seen in the pigments, except for $\mathrm{Chl} \mathrm{a} / \mathrm{b}$ which displayed higher levels after the second cold spell and Car/Chl which had a tendency to increase after the cold spells.

\section{Seasonal variation in ChIF spectra}

The ChIF spectra of pine needles measured at room temperature and at standard illumination $\left(\mathrm{F}_{\lambda}\right.$, Fig. 4a-c) was used here as a proxy of variations in the spectrally resolved fluorescence yield. $F_{\lambda}$ experienced strong seasonal changes during the study period, mainly in terms of intensity but also in shape. For example, the red peak near $690 \mathrm{~nm}$ was nearly absent during winter (Fig. 4a,b), but gradually reappeared towards summer (Fig. 4c). Both red ( $\left.F_{690}\right)$ and far-red (F 740$)$ ChIF (Fig. 4d) increased from early

spring to summer with a larger change in $\mathrm{F}_{740 .}$. Integrated $\operatorname{ChIF}\left(\int_{660}^{780} F d \lambda\right.$, Fig. $\left.4 \mathrm{e}\right)$, used here for comparison with the spectrally averaged $\Phi_{F}$, presented a similar 
seasonal pattern with the rest of photosynthetic parameters. Both $\Phi_{F}$ (Fig. $2 d$ ) and $\int_{660}^{780} F d \lambda$ (Fig. 4 e) varied seasonally by a factor of 2 . The $\mathrm{F}_{690} / \mathrm{F}_{740}$ ratio drastically decreased from 0.5 to 0.4 in response to the first cold spell, and did not reverse to 0.5 until several weeks later (Fig. 4f). Later on, the ratio decreased again to about 0.45 by the end of the study period, coinciding with the increase in total Chl (Fig. 3a) and $F_{\lambda}$ (Fig. 4d).

\section{Principal component analysis}

Three principal components explained $99.8 \%$ of the variation in ChIF spectra during the study period (Fig. 5). PC1 explained $98.8 \%$ of variance of ChIF spectra across the spring recovery (Fig. 5a) and exhibited a clear and similar seasonal pattern (Fig. 5b) to that of red, far-red, and integrated ChIF (Fig. 4d,e). The spectral weights and intensity of PC1 reflected the shape and seasonal variation in $\Phi_{F}$. In contrast, PC2 (Fig. 5c) explained only $0.8 \%$ of variance but its spectral weights presented a strong and wavelength dependent shape reflecting differences in red and far-red ChIF. PC2 potentially indicates seasonal changes in ChIF reabsorption (i.e. $f_{\mathrm{esc}}(\lambda)$ in Eqn.1), changes in energy redistribution between PSII and PSI, or changes in the emission spectra at the photosystem level. Remarkably, a drastic increase of PC2 (Fig. 5d) was detected upon the first cold spell (solid and vertical black line), and later on during summer when foliar Chl content tended to increase (Fig. 3a). Overall, the seasonal pattern of PC2 closely resembled the mirror image of $F_{690} / F_{740}$ (Fig. 4f). PC3 explained

only $0.2 \%$ of variance (Fig. $5 e$ ) and displayed no clear seasonal trend other than a sharp decrease at the end of April (Fig. 5f). 
Seasonal correlations between photosynthetic parameters and spectral ChIF

Measurements of red, far-red and integral ChIF under standardized conditions were strongly correlated with field photosynthetic parameters $\alpha(r: 0.81-0.83), \beta(r: 0.84-0.86)$ and Fv/FM (r: 0.87-0.89) ( $P<0.001$ for all; Fig. 6 and Fig. S4). In contrast, no significant relationships between $F_{690} / F_{740}$ and photosynthetic parameters were found. Red ( $\left.F_{690}\right)$ and far-red $\left(F_{740}\right)$ ChIF were strongly and negatively correlated also with leaf carotenoid content ( $r$ : -0.9 and -0.87 , respectively) and NPQs $(r:-0.86$ and -0.83 , respectively), and positively related with $\Phi_{\mathrm{F}}(r: 0.73$ and 0.71 , respectively) and $\mathrm{PQs}$ (r: 0.74 and 0.71 , respectively) ( $P<0.001$ for all; Fig. 6 and Fig. S4). In fact, NPQs and leaf carotenoid content were the two factors that displayed the strongest (negative) correlation with the spring recovery of photosynthesis in terms of $\alpha, \beta$, and $\mathrm{Fv} / \mathrm{F}_{\mathrm{M}}$. No significant relationship was observed between red or far-red ChIF and total Chl or $A_{\text {(PAR) }}$ (Fig. S4).

As for the principal components, PC1 was correlated strongly with $\mathrm{Fv} / \mathrm{F}_{\mathrm{M}}(r=0.87)$, and negatively correlated with carotenoid, Car/Chl, and NPQs (r: -0.87 to -0.83 ), and had a significant but slightly lower relationship with $\Phi_{\mathrm{F}}$ and $\mathrm{PQs}_{\mathrm{s}}(r=0.72)(P<0.001$ for all; Fig. 6 and Fig. S4). PC2 was highly and negatively correlated with $\mathrm{F}_{690} / \mathrm{F}_{740}(r=-$ 0.92; $P<0.001)$ but was not significantly correlated with $A_{\mathrm{T}(\mathrm{PAR})}(r=0.51)$ and total $\mathrm{Chl}$ $(r=0.37)$. Finally, PC3 was only marginally correlated with $\mathrm{Chl} \mathrm{a} / \mathrm{b}(r=0.45 ; P=0.06)$.

We also conducted a systematic assessment of the seasonal correlations between different ChIF emission wavelengths and photosynthetic parameters (Fig. 7). The results indicated that both red and far-red ChIF wavelengths were strongly correlated with the spring recovery of photosynthesis $(P<0.001$ for all), represented here by the photosynthetic parameters $\alpha$ and $\beta$ (Fig. 7a), with red wavelengths displaying stronger 
correlations than far-red wavelengths. Correlations were also stronger for $\beta$, compared to $a$ across the whole spectral range, which is not surprising since our spectral measurements were conducted at high light. The strength of the correlation decreased between the two ChIF emission peak, with highest RMSE (data not shown). As expected, a wavelength dependency in the slope of $\alpha(\beta)$ vs. $F_{\lambda}$ was also observed (Fig. 7b), further emphasizing that the ratio $\operatorname{LUE} / \Phi_{F}(\lambda)$ (as in Eqn. 3) was dependent on ChIF emission wavelengths. Positive intercepts of $\mathrm{F}_{\lambda}$ vs. $\alpha(\beta)$ (Fig. 7c; with ranges of 0.15 to $0.95 \mathrm{~mW} \mathrm{~m}^{-2} \mathrm{sr}^{-1} \mathrm{~nm}^{-1}$ ) were obtained for both parameters and across wavelengths, indicating positive ChIF emission when photosynthetic gas exchange approaches zero.

Additionally, all the main ChIF emission wavelengths from 680 to $770 \mathrm{~nm}$ were well correlated with $\Phi_{\mathrm{F}}(P<0.001$ for all), and presented slightly stronger relationships in the red region than far-red (Fig. S5a). This was consistent with better correlations of ChIF with photosynthetic parameters in the red than in the far-red wavelengths (Fig. 7a). Further, when comparing $\mathrm{F}_{\lambda}$ to $\int_{660}^{780} F d \lambda$, red wavelengths presented slightly lower correlations (Fig. S5b), reflecting that red ChIF fluorescence wavelengths account for a source of independent information not conveyed by broadband ChIF.

\section{Discussion}

We followed the spectral response of ChIF during the spring recovery of photosynthesis. We found an across wavelength increase in ChIF 'level' well correlated with photosynthetic parameters, and additional subtler changes in spectral shape over time. Critically, photosystems in overwintering evergreens undergo major structural and biochemical adjustments during the non-photosynthetic season (Adams 
\& Demmig-Adams 1994; Ottander et al. 1995; Gilmore \& Ball 2000; Ensminger et al. 2004; Verhoeven 2014), which were reflected in the variation of the measured ChIF spectra.

Seasonal variation in leaf-level ChIF spectra and its controls

We used PCA analysis to separate and quantify the relative roles of different components of variation in the seasonal ChIF dynamics of pine needles. We found that $98.8 \%$ of the seasonal variation in ChIF spectra of needles was explained by changes in ChIF level (PC1) with only a marginal $1 \%$ of variation associated with additional changes in shape (with PC2 explaining $0.8 \%$ ). Factors contributing to these components of variation are discussed next.

Lack of correlation between $\mathrm{F}_{690}, \mathrm{~F}_{740}$ (and PC1), and total Chl content or $A_{T(P A R)}$ (Figs. 6 and S4) evidenced the minor role of PAR absorption in driving the seasonality of ChIF during the spring recovery. In the present study Chl content remained relatively stable (Fig. 3a). This is at odds with previous work where significant seasonal changes in Chl content have been observed in Scots pine needles (Ottander et al. 1995; Ensminger et al. 2004, Porcar-Castell et al. 2012), and other evergreen species (Wong \& Gamon 2015). It is unclear why we observed such differences in pigments; but considering the alternative scenario where $\mathrm{Chl}$ did change during the season, and as the bulk of the spring recovery of ChIF in Scots pine needles has been shown to precede the summer increase in foliar Chl content by about two weeks (Porcar-Castell et al. 2008a), changes in leaf PAR absorption ( $A$, Eqn.1) will likely remain of lesser importance in controlling the seasonality in leaf-level $\operatorname{SIF}(\lambda)$ in evergreen conifers. We also did not find evidence of an inverse and persistent relationship between red/far- 
red ratio and foliar Chl content across the study period (Figs. 6 and S4), as would follow from the general $\mathrm{Chl}$ reabsorption theory (Fig. 4A in Gitelson, Buschmann \& Lichtenthaler 1999; Fig. 4 in Buschmann 2007). This result demonstrates that, in addition to foliar Chl content, other factors also influence the shape of the ChIF spectra.

Seasonal changes in both $\mathrm{F}_{690}$ and $\mathrm{F}_{740}$ (and PC1) were strongly related to seasonal variation in foliar carotenoid content, NPQs, and to a lesser extent PQs (Fig. 6). The mechanisms that drive NPQs in overwintering evergreens (understood as the sustained enhancement in the capacity for thermal dissipation of excitation energy), remain under intense investigation (Demmig-Adams \& Adams 2006; Verhoeven 2014; Ruban 2016; Malnoë 2018). NPQs in evergreens has been associated to: the accumulation of carotenoids (especially zeaxanthin) relative to Chl (Adams \& DemmigAdams 1994; Ensminger et al. 2004; Zarter et al. 2006a; Porcar-Castell et al. 2012), the accumulation of damaged or non-functional PSII reaction centers coupled to a reduction in the PSII core D1 protein (Ottander et al. 1995; Ensminger et al. 2004; Ebbert, Adams, Mattoo, Sokolenko \& Demmig-Adams 2005), the presence and accumulation of early-light induced proteins (Elips) with or without concomitant changes in minor antenna PsbS proteins (Ensminger et al. 2004; Ebbert et al. 2005; Zarter et al. 2006b; Verhoeven 2014), the aggregation of light-harvesting complexes of PSII (LHCII) (Horton et al. 1991; Ottander et al. 1995; Busch, Hüner \& Ensminger 2007; Ruban 2018), and the unstacking of the thylakoid membrane (Demmig-Adams et al. 2015).

Reversible forms of NPQ, which operate in time scales of seconds to minutes, (e.g. energy-dependent or zeaxanthin-dependent quenching $q E$ and $q Z$, respectively) (Verhoeven 2014; Malnoë 2018), are known to predominantly quench ChIF associated with PSII units with no apparent effect on PSI ChIF (Genty et al. 1990; Franck et al. 
2002). As a result, because the ChIF contribution from PSI is much larger around the far-red peak (Genty et al. 1990; Pfündel 1998; Franck et al. 2002), an increase in qE or $\mathrm{qZ}$ results in a reduction in the red/far-red ChIF ratio (Agati, Mazzinghi, Fusi \& Ambrosini 1995; Agati et al. 2000). If the PSI ChIF contribution would be also insensitive to NPQs, we would have expected a similar decrease in $\mathrm{F}_{690} / \mathrm{F}_{740}$ in response to the seasonal accumulation of NPQs. This scenario was not fully supported by our observations because the extremes of variation in $F_{690} / F_{740}$ ratio (observed during March, Fig. 4f) took place under comparable Chl and NPQs levels (Figs. 2f and 3a), suggesting that PSI ChIF contribution is dynamic at the seasonal scale.

Seasonal changes in the ChIF ratio are clearly driven by multiple controls. For example, $F_{690} / F_{740}$ decreased from 0.5 to 0.4 in response to the first cold spell, along with an increase in NPQs (Fig. 2f) and in PC2 (Fig. 5d) which occurred under rather stable Chl content (Fig. 3a). This phenomena could denote a structural reorganization at the level of LHCII (increased reabsorption due to aggregation), or thylakoid membrane unstacking (promoting energetic connectivity between PSII and PSI units) accompanying the accumulation of NPQs. In fact, similar decreases in red/far-red ChIF ratio have been reported in response to reversible NPQ-induced oligomerization of LHCll complexes (Miloslavina et al. 2008; Jahns \& Holzwarth 2012). Later on, in midMay and July we registered a slight increase in foliar Chl content (Fig. 3a) accompanied by a decrease in the $F_{690} / F_{740}$ ratio (Fig. $4 f$ ), and under rather stable NPQs (Fig. 2f) corresponding to the previous characterized relationship between leaf Chl content and the ChIF ratio (Gitelson et al. 1999). Overall, further experimental and modelling studies are needed to clarify the mechanisms that drive the dynamics in the ChIF spectra in overwintering evergreens. 


\section{Wavelength dependency between ChIF and photosynthesis}

We found that all the main ChIF emission wavelengths $(680-770 \mathrm{~nm})$ were correlated with and capable of tracking the photosynthetic spring recovery in boreal evergreen foliage (Fig. 7a). This finding was consistent with the dominant role of NPQs in controlling the seasonal variability in the ChIF level across wavelengths (PC1; Fig. $5 a, b)$. It is important to note however that the relative contributions of the variation in spectral shape (1\% for PC2+PC3) and ChIF level (98.8\% for PC1) to total seasonal variation in ChIF spectral properties could have been very different in a different species or under a different set of environmental conditions, encouraging further seasonal studies across other species and biomes.

Slightly higher correlations (Fig. 7a) and slopes (Fig. 7b) were found between red wavelengths of $F_{\lambda}$ and $\alpha$ and $\beta$. Similar results have been reported at the canopy scale based on model simulations (Verrelst et al. 2015; Liu et al. 2019) and experimental data (Cheng et al. 2013; Campbell et al. 2019; Magney et al. 2019a). At the leaf-level, the higher correlation in red wavelengths could point to interferences with the dynamics or PSI ChIF in the far-red wavelengths. In fact, the spectral shape of the intercept (Fig. 7c), which represents the background ChIF spectra at zero photosynthesis, had a high resemblance to the typical spectral shape of PSI ChIF, although the peak was slightly red-shifted $(740 \mathrm{~nm})$ compared to earlier studies in nondownregulated leaves of barley (722 nm) (Franck et al. 2002) or maize PSI particles (725-730 nm) (Croce, Dorra, Holzwarth \& Jennings 2000). Further work to characterize and identify the drivers of this background ChIF signal, which may have important implications for interpretation of SIF data over boreal evergreen regions, is needed. 
Implications at the larger scale

SIF is a promising methodology for the estimation of GPP dynamics in terrestrial ecosystems either using statistical methods based on Eqn. 3 (Guanter et al. 2014; Sun et al. 2017; Li et al. 2018), or by assimilation into the photosynthetic modules of land surface models (Lee et al. 2015; Thum et al. 2017; Macbean et al. 2018). SIF could be particularly useful for evergreen ecosystems by capturing part of the temporal dynamics of GPP that remains hidden to traditional reflectance-based vegetation indices due to low variation in greenness (Walther et al. 2016; Smith et al. 2018; Zuromski et al. 2018; Magney et al. 2019a; Nichol et al. 2019).

Overall, our results indicate that current Fraunhofer- and oxygen-based methods to retrieve SIF across different wavelengths in the red and near-infrared regions (Meroni et al. 2009; Lu, Cheng, Li \& Tang 2018) have similar intrinsic potential to capture the leaf-level spring recovery of photosynthesis in boreal evergreen forests. Importantly, when upscaling from the leaf to the canopy and landscape level, the constancy assumption behind the LUE/ $\Phi_{F}(\lambda)$ factor in Eqn. 3 will be further complicated by spatial variation in physiological factors caused by within canopy light and temperature gradients or species composition (Porcar-Castell et al. 2014; Sun et al. 2017). Similarly, canopy-level $f_{e s c}$ (Eqn. 3) will be also affected by seasonal dynamics in canopy structure related to the phenology of the multiple components in the ecosystem, including the understory (Majasalmi, Stenberg \& Rautiainen 2017; Liu et al. 2019). 


\section{Conclusions}

We demonstrated that red and far-red ChIF emission wavelengths were able to transmit the optical signature of the spring recovery of photosynthesis in boreal evergreen needles. The dynamics of the spectral signature were mediated by the complex and highly articulated process of sustained regulatory thermal dissipation or NPQs, which effectively quenches all ChIF wavelengths. Although changes in the shape of the ChIF spectra explained only a marginal proportion of the observed seasonality, the information content embedded in these changes could be highly informative. Specifically, the rapid decrease in the $F_{690} / F_{740}$ ratio upon the first cold spell suggests that in addition to $\mathrm{Chl}$ content, $\mathrm{F}_{690} / \mathrm{F}_{740}$ can also convey information on the structural organization in the thylakoid membrane in overwintering evergreens, which could help to better constrain the assimilation of SIF data into models of photosynthesis (Macbean et al. 2018; Raczka et al. 2019). Further investigations across species and scales will be required to fully characterize the information potentially embedded in the spectral dynamics of SIF, in support of multispectral SIF retrievals from towers, drones, airplanes as well as satellite missions such as current TROPOspheric Monitoring Instrument, TROPOMI, onboard Sentinel-5 (Guanter et al. 2015; Köhler et al. 2018) or future Fluorescence Explorer mission, FLEX (Drusch et al. 2017).

Acknowledgements: We acknowledge the financial support from the Academy of Finland $(288039,293443,319211,272041)$, the COST Action ES1309/OPTIMISE, the

European Research Council Synergy grant SyG-2013-610028 IMBALANCE-P, the Spanish Government project CGL2016-79835-P, the Catalan Government project SGR 2014-274, and the Funds from the University of Helsinki (Grant 490116). HR was 
supported by EU LIFE 12 ENV/FI/000409 Monimet. CZ gratefully acknowledges the support from the China Scholarship Council.

Conflict of interest: The authors have no conflicts of interest to declare.

Author Contribution: Albert Porcar-Castell, Jon Atherton, Iolanda Filella, Josep Peñuelas and Jaana Bäck conceived and designed the study; Chao Zhang and Albert Porcar-Castell carried out the optical measurements; Chao Zhang and Jon Atherton conducted the majority of the data analysis; Pasi Kolari estimated the photosynthetic parameters; Juho Aalto carried out and processed the field gas exchange data at SMEAR-II station; Hanna Ruhanen conducted the pigments analysis; Chao Zhang and Albert Porcar-Castell wrote the paper with contributions from all authors.

\section{References}

Aalto J., Kolari P., Hari P., Kerminen V.M., Schiestl-Aalto P., Aaltonen H., ... Bäck J. (2014) New foliage growth is a significant, unaccounted source for volatiles in boreal evergreen forests. Biogeosciences 11, 1331-1344.

Adams W.W. \& Demmig-Adams B. (1994) Carotenoid composition and down regulation of photosystem II in three conifer species during the winter. Physiologia Plantarum 92, 451-458.

Agati G., Cerovic Z.G. \& Moya I. (2000) The effect of decreasing temperature up to chilling values on the in vivo F685/F735 chlorophyll fluorescence ratio in Phaseolus vulgaris and Pisum sativum: the role of the photosystem I 
contribution to the $735 \mathrm{~nm}$ fluorescence band. Photochemistry and Photobiology $72,75-84$.

Agati G., Mazzinghi P., Fusi F. \& Ambrosini I. (1995) The F685/F730 chlorophyll fluorescence ratio as a tool in plant physiology: response to physiological and environmental factors. Journal of Plant Physiology 145, 228-238.

Alonso L., Gómez-chova L., Vila-francés J., Amorós-lópez J., Guanter L., Calpe J. \& Moreno J. (2007) Sensitivity analysis of the Fraunhofer Line Discrimination method for the measurement of chlorophyll fluorescence using a field spectroradiometer. IEEE, 3756-3759.

Baker N.R. (2008) Chlorophyll fluorescence: a probe of photosynthesis in vivo. Annual review of plant biology 59, 89-113.

Barber J., Malkin S. \& Telfer A. (1989) The origin of chlorophyll fluorescence in vivo and its quenching by the photosystem II reaction centre. Philosophical Transactions of the Royal Society B: Biological Sciences 323, 227-239.

Busch F., Hüner N.P.A. \& Ensminger I. (2007) Increased air temperature during simulated autumn conditions does not increase photosynthetic carbon gain but affects the dissipation of excess energy in seedlings of the evergreen conifer jack pine. Plant Physiology 143, 1242-1251.

Buschmann C. (2007) Variability and application of the chlorophyll fluorescence emission ratio red/far-red of leaves. Photosynthesis Research 92, 261-271.

Campbell P.K., Huemmrich K.F., Middleton E.M., Ward L.A., Julitta T., Daughtry C.S., ... Kustas W.P. (2019) Diurnal and seasonal variations in chlorophyll fluorescence associated with photosynthesis at leaf and canopy scales. Remote Sensing 11, 1-36. 
Cheng Y., Middleton E.M., Zhang Q., Huemmrich K.F., Campbell P.K.E., Corp L.A., ... Daughtry C.S. (2013) Integrating solar induced fluorescence and the photochemical reflectance index for estimating gross primary production in a cornfield. Remote Sensing 5, 6857-6879.

Croce R., Dorra D., Holzwarth A.R. \& Jennings R.C. (2000) Fluorescence decay and spectral evolution in intact photosystem I of higher plants. Biochemistry 39, $6341-6348$.

Damm A., Guanter L., Paul-limoges E., Tol C. Van Der, Hueni A., Buchmann N., ... Schaepman M.E. (2015) Far-red sun-induced chlorophyll fluorescence shows ecosystem-specific relationships to gross primary production: An assessment based on observational and modeling approaches. Remote Sensing of Environment 166, 91-105.

Demmig-Adams B. \& Adams W.W. (2006) Photoprotection in an ecological context: the remarkable complexity of thermal energy dissipation. New Phytologist 172 , $11-21$

Demmig-Adams B., Muller O., Stewart J.J., Cohu C.M. \& Adams W.W. (2015) Chloroplast thylakoid structure in evergreen leaves employing strong thermal energy dissipation. Journal of Photochemistry and Photobiology B: Biology 152, 357-366.

Drusch M., Moreno J., Del Bello U., Franco R., Goulas Y., Huth A., ... Verhoef W. (2017) The FLuorescence EXplorer Mission Concept-ESA's Earth Explorer 8. IEEE Transactions on Geoscience and Remote Sensing 55, 1273-1284.

Ebbert V., Adams W.W., Mattoo A.K., Sokolenko A. \& Demmig-Adams B. (2005) Upregulation of a photosystem II core protein phosphatase inhibitor and sustained 
D1 phosphorylation in zeaxanthin-retaining, photoinhibited needles of overwintering Douglas fir. Plant, Cell and Environment 28, 232-240.

Ensminger I., Sveshnikov D., Campbell D.A.., Funk C., Jansson S., Lloyd J., ... Öquist G. (2004) Intermittent low temperatures constrain spring recovery of photosynthesis in boreal Scots pine forests. Global Change Biology 10, 9951008 .

Franck F., Juneau P. \& Popovic R. (2002) Resolution of the Photosystem I and Photosystem II contributions to chlorophyll fluorescence of intact leaves at room temperature. Biochimica et Biophysica Acta - Bioenergetics 1556, 239-246.

Frankenberg C. \& Berry J. (2018) Solar induced chlorophyll fluorescence : origins , relation to photosynthesis and retrieval. In Reference Module in Earth Systems and Environmental Sciences: Comprehensive Remote Sensing, Elsevier, Oxford. pp. 143-162. Elsevier.

Frankenberg C., Fisher J.B., Worden J., Badgley G., Saatchi S.S., Lee J.E., ... Yokota T. (2011) New global observations of the terrestrial carbon cycle from GOSAT: Patterns of plant fluorescence with gross primary productivity. Geophysical Research Letters 38, 1-6.

Frankenberg C., O'Dell C., Berry J., Guanter L., Joiner J., Köhler P., ... Taylor T.E. (2014) Prospects for chlorophyll fluorescence remote sensing from the Orbiting Carbon Observatory-2. Remote Sensing of Environment 147, 1-12.

Genty B., Wonders J. \& Baker N.R. (1990) Non-photochemical quenching of $F_{\circ}$ in leaves is emission wavelength dependent: consequences for quenching analysis and its interpretation. Photosynthesis Research 26, 133-139.

Gilmore A.M. \& Ball M.C. (2000) Protection and storage of chlorophyll in 
overwintering evergreens. Proceedings of the National Academy of Sciences $97,11098-11101$.

Gitelson A.A., Buschmann C. \& Lichtenthaler H.K. (1999) The chlorophyll fluorescence ratio $F_{735} / F_{700}$ as an accurate measure of the chlorophyll content in plants. Remote Sensing of Environment 69, 296-302.

Govindjee G. (1995) Sixty-three years since Kautsky: chlorophyll a fluorescence. Australian Journal of Plant Physiology 22, 131-160.

Guanter L., Aben I., Tol P., Krijger J.M., Hollstein A., Köhler P., ... Landgraf J. (2015) Potential of the TROPOspheric Monitoring Instrument (TROPOMI) onboard the Sentinel-5 Precursor for the monitoring of terrestrial chlorophyll fluorescence. Atmospheric Measurement Techniques 8, 1337-1352.

Guanter L., Zhang Y., Jung M., Joiner J., Voigt M., Berry J.A., .. Moran M.S. (2014) Global and time-resolved monitoring of crop photosynthesis with chlorophyll fluorescence. Proceedings of the National Academy of Sciences, 1-7.

Hari P. \& Kulmala M. (2005) Station for measuring ecosystem-atmosphere relations (SMEAR II). Boreal Environment Research 10, 351-322.

Hari P., Mäkelä A., Korpilahti E. \& Holmberg M. (1986) Optimal control of gas exchange. Tree Physiology 2, 169-175.

Horton P., Ruban A. V., Rees D., Pascal A.A., Noctor G. \& Young A.J. (1991) Control of the light-harvesting function of chloroplast membranes by aggregation of the LHCII chlorophyll-protein complex. FEBS Letters 292, 1-4.

Huang W., Yang Y.J., Hu H. \& Zhang S.B. (2016) Seasonal variations in photosystem I compared with photosystem II of three alpine evergreen broadleaf tree species. Journal of Photochemistry and Photobiology B: Biology 165 , 
71-79.

Idle D.B. \& Proctor C.W. (1983) An integrating sphere leaf chamber. Plant, Cell and Environment 6, 437-439.

IPCC-SR15 (2018) Special report IPCC. "Global Warming of $1.5^{\circ} \mathrm{C}$."

Jahns P. \& Holzwarth A.R. (2012) The role of the xanthophyll cycle and of lutein in photoprotection of photosystem II. Biochimica et Biophysica Acta Bioenergetics 1817, 182-193.

Joiner J., Yoshida Y., Guanter L. \& Middleton E.M. (2016) New methods for the retrieval of chlorophyll red fluorescence from hyperspectral satellite instruments: simulations and application to GOME-2 and SCIAMACHY. Atmospheric Measurement Techniques 9, 3939-3967.

Kitajima M. \& Butler W.L. (1975) Quenching of chlorophyll fluorescence and primary photochemistry in chloroplasts by dibromothymoquinone. Biochimica et Biophysica Acta 376, 105-115.

Köhler P., Frankenberg C., Magney T.S., Guanter L., Joiner J. \& Landgraf J. (2018) Global retrievals of solar-induced chlorophyll fluorescence with TROPOMI: first results and intersensor comparison to OCO-2. Geophysical Research Letters $45,10,456-10,463$.

Kolari P., Bäck J., Taipale R., Ruuskanen T.M., Kajos M.K., Rinne J., ... Hari P. (2012) Evaluation of accuracy in measurements of VOC emissions with dynamic chamber system. Atmospheric Environment 62, 344-351.

Kolari P., Chan T., Porcar-Castell A., Bäck J., Nikinmaa E. \& Juurola E. (2014) Field and controlled environment measurements show strong seasonal acclimation in photosynthesis and respiration potential in boreal Scots pine. Frontiers in Plant 
Science 5, 717.

Kolari P., Lappalainen H.K., Hänninen H. \& Hari P. (2007) Relationship between temperature and the seasonal course of photosynthesis in Scots pine at northern timberline and in southern boreal zone. Tellus B: Chemical and Physical Meteorology 59B, 542-552.

Lee J.-E., Berry J.A., van der Tol C., Yang X., Guanter L., Damm A., ... Frankenberg C. (2015) Simulations of chlorophyll fluorescence incorporated into the Community Land Model version 4. Global Change Biology 21, 3469-3477.

Li X., Xiao J., He B., Arain M.A., Beringer J., Desai A.R., ... Varlagin A. (2018) Solarinduced chlorophyll fluorescence is strongly correlated with terrestrial photosynthesis for a wide variety of biomes: First global analysis based on OCO-2 and flux tower observations. Global Change Biology, 1-19.

Liu W., Atherton J., Mõttus M., Gastellu-Etchegorry J.P., Malenovský Z., Raumonen P., ... Porcar-Castell A. (2019) Simulating solar-induced chlorophyll fluorescence in a boreal forest stand reconstructed from terrestrial laser scanning measurements. Remote Sensing of Environment in press.

Lu X., Cheng X., Li X. \& Tang J. (2018) Opportunities and challenges of applications of satellite-derived sun-induced fluorescence at relatively high spatial resolution. Science of the Total Environment 619-620, 649-653.

Macbean N., Maignan F., Bacour C., Lewis P., Guanter L., Köhler P., ... Disney M. (2018) Strong constraint on modelled global carbon uptake using solar-induced chlorophyll fluorescence data. Scientific reports, 1-12.

Magney T.S., Bowling D.R., Logan B., Grossmann K., Stutz J., Blanken P., ... Frankenberg C. (2019a) Mechanistic evidence for tracking the seasonality of 
photosynthesis with solar-induced fluorescence. Proceedings of the National Academy of Sciences 116, 11640-11645.

Magney T.S., Frankenberg C., Köhler P., North G., Davis T.S., Dold C., ... PorcarCastell A. (2019b) Disentangling changes in the spectral shape of chlorophyll fluorescence: Implications for remote sensing of photosynthesis. Journal of Geophysical Research: Biogeosciences 124, 1-17.

Majasalmi T., Stenberg P. \& Rautiainen M. (2017) Comparison of ground and satellite-based methods for estimating stand-level fPAR in a boreal forest. Agricultural and Forest Meteorology 232, 422-432.

Malnoë $A_{\text {, }}$ (2018) Photoinhibition or photoprotection of photosynthesis? Update on the (newly termed) sustained quenching component $\mathrm{qH}$. Environmental and Experimental Botany 154, 123-133.

Meroni M., Rossini M., Guanter L., Alonso L., Rascher U., Colombo R. \& Moreno J. (2009) Remote sensing of solar-induced chlorophyll fluorescence: review of methods and applications. Remote Sensing of Environment 113, 2037-2051.

Migliavacca M., Perez-Priego O., Rossini M., El-Madany T.S., Moreno G., van der Tol C., ... Reichstein M. (2017) Plant functional traits and canopy structure control the relationship between photosynthetic $\mathrm{CO}_{2}$ uptake and far-red suninduced fluorescence in a Mediterranean grassland under different nutrient availability. New Phytologist 214, 1078-1091.

Miloslavina Y., Wehner A., Lambrev P.H., Wientjes E., Reus M., Garab G., ... Holzwarth A.R. (2008) Far-red fluorescence: A direct spectroscopic marker for LHCll oligomer formation in non-photochemical quenching. FEBS Letters 582, $3625-3631$ 
Monteith J.L. (1972) Solar radiation and productivity in tropical ecosystems. Journal of Applied Ecology 9, 747-766.

Murata N., Takahashi S., Nishiyama Y. \& Allakhverdiev S.I. (2007) Photoinhibition of photosystem II under environmental stress. Biochimica et Biophysica Acta Bioenergetics 1767, 414-421.

Murchie E.H. \& Lawson T. (2013) Chlorophyll fluorescence analysis: a guide to good practice and understanding some new applications. Journal of Experimental Botany 64, 3983-3998.

Nichol C., Drolet G., Porcar-Castell A., Wade T., Sabater N., Middleton E., ... Atherton J. (2019) Seasonal solar induced chlorophyll fluorescence and photosynthesis in a boreal Scots pine canopy. Remote Sensing 11, 273.

Olascoaga B., Mac Arthur A., Atherton J. \& Porcar-Castell A. (2016) A comparison of methods to estimate photosynthetic light absorption in leaves with contrasting morphology. Tree Physiology 36, 368-379.

Öquist G., Chow W.S. \& Anderson J.M. (1992) Photoinhibition of photosynthesis represents a mechanism for the long-term regulation of photosystem II. Planta $186,450-460$.

Öquist G., Hällgren J.E. \& Brunes L. (1978) An apparatus for measuring photosynthetic quantum yields and quanta absorption spectra of intact plants. Plant, Cell and Environment 1, 21-27.

Öquist G. \& Huner N.P.A. (2003) Photosynthesis of overwintering evergreen plants. Annual Review of Plant Biology 54, 329-355.

Ottander C., Campbell D. \& Öquist G. (1995) Seasonal changes in photosystem II organisation and pigment composition in Pinus sylvestris. Planta 197, 176-183. 
Ottander C. \& Öquist G. (1991) Recovery of photosynthesis in winter-stressed Scots pine. Plant, Cell and Environment 14, 345-349.

Palombi L., Cecchi G., Lognoli D., Raimondi V., Toci G. \& Agati G. (2011) A retrieval algorithm to evaluate the photosystem I and photosystem II spectral contributions to leaf chlorophyll fluorescence at physiological temperatures.

Photosynthesis research 108, 225-239.

Parazoo N.C., Arneth A., Pugh T.A.M., Smith B., Steiner N., Luus K., ... Miller C. (2018) Spring photosynthetic onset and net $\mathrm{CO}_{2}$ uptake in Alaska triggered by landscape thawing. Global Change Biology, 3416-3435.

Parazoo N.C., Bowman K., Fisher J.B., Frankenberg C., Jones D.B.A., Cescatti A., ... Montagnani L. (2014) Terrestrial gross primary production inferred from satellite fluorescence and vegetation models. Global Change Biology 20, 31033121.

Pfündel E. (1998) Estimating the contribution of photosystem I to leaf chlorophyll fluorescence. Photosynthesis Research 56, 185-195.

Pfündel E.E., Klughammer C., Meister A. \& Cerovic Z.G. (2013) Deriving fluorometer-specific values of relative PSI fluorescence intensity from quenching of $F_{0}$ fluorescence in leaves of Arabidopsis thaliana and Zea mays.

Photosynthesis research 114, 189-206.

Pirinen P., Simola H., Aalto J., Kaukoranta J.-P., Karlsson P. \& Ruuhela R. (2012) Tilastoja suomen ilmastosta 1981-2010. (Climatological statistics of Finland 1981-2010).

Porcar-Castell A. (2011) A high-resolution portrait of the annual dynamics of photochemical and non-photochemical quenching in needles of Pinus sylvestris. 
Physiologia Plantarum 143, 139-153.

Porcar-Castell A., Mac Arthur A., Rossini M., Eklundh L., Pacheco-Labrador J., Anderson K., ... Vescovo L. (2015) EUROSPEC: At the interface between remote-sensing and ecosystem $\mathrm{CO}_{2}$ flux measurements in Europe.

Biogeosciences 12, 6103-6124.

Porcar-Castell A., Garcia-Plazaola J.I., Nichol C.J., Kolari P., Olascoaga B., Kuusinen N., ... Nikinmaa E. (2012) Physiology of the seasonal relationship between the photochemical reflectance index and photosynthetic light use efficiency. Oecologia 170, 313-323.

Porcar-Castell A., Juurola E., Ensminger I., Berninger F., Hari P. \& Nikinmaa E. (2008a) Seasonal acclimation of photosystem II in Pinus sylvestris. II. Using the rate constants of sustained thermal energy dissipation and photochemistry to study the effect of the light environment. Tree physiology 28, 1483-1491.

Porcar-Castell A., Pfündel E., Korhonen J.F.J. \& Juurola E. (2008b) A new monitoring PAM fluorometer ( MONI-PAM) to study the short- and long-term acclimation of photosystem II in field conditions. Photosynthesis research 96, $173-179$.

Porcar-Castell A., Tyystjärvi E., Atherton J., van der Tol C., Flexas J., Pfündel E.E., ... Berry J.A. (2014) Linking chlorophyll a fluorescence to photosynthesis for remote sensing applications: mechanisms and challenges. Journal of Experimental Botany 65, 4065-4095.

Quéré C. Le, Andrew R.M., Friedlingstein P., Sitch S., Hauck J., Pongratz J., ... Adrie and B.Z. (2018) Global Carbon Budget 2018. Earth System Science Data 10, 2141-2194. 
Raczka B., Porcar-Castell A., Magney T., Lee J.E., Köhler P., Frankenberg C., ... Bowling D.R. (2019) Sustained non-photochemical quenching shapes the seasonal pattern of solar-induced fluorescence at a high-elevation evergreen forest. Journal of Geophysical Research: Biogeosciences 124.

Rajewicz P., Atherton J., Alonso L. \& Porcar-Castell A. (2019) Leaf-level spectral fluorescence measurements: comparing methodologies for broadleaves and needles. Remote Sensing 11, 1-20.

Rascher U., Alonso L., Burkart A., Cilia C., Cogliati S., Colombo R., ... Zemek F. (2015) Sun-induced fluorescence - a new probe of photosynthesis: First maps from the imaging spectrometer HyPlant. Global Change Biology 21, 4673-4684.

Romero J.M., Cordon G.B. \& Lagorio M.G. (2018) Modeling re-absorption of fluorescence from the leaf to the canopy level. Remote Sensing of Environment 204, 138-146.

Ruban A. V. (2018) Light harvesting control in plants. FEBS Letters 592, 3030-3039.

Ruban A. V (2016) Nonphotochemical chlorophyll fluorescence quenching: mechanism and effectiveness in protecting plants from photodamage. Plant physiology 170, 1903-1916.

Ruban A. V, Johnson M.P. \& Duffy C.D.P. (2012) The photoprotective molecular switch in the photosystem II antenna. Biochimica et Biophysica Acta 1817, 167181.

Smith P., Bustamante M., Ahammad H., Clark H., Dong H., Elsiddig E.A., ... Tubiello F.N. (2014) Agriculture, Forestry and Other Land Use (AFOLU). Climate Change 2014: Mitigation of Climate Change. Contribution of Working Group III to the Fifth Assessment Report of the Intergovernmental Panel on Climate 
Change, 811-922.

Smith W.K., Biederman J.A., Scott R.L., Moore D.J.P., He M., Kimball J.S., ... Litvak M.E. (2018) Chlorophyll fluorescence better captures seasonal and interannual gross primary productivity dynamics across dryland ecosystems of southwestern North America. Geophysical Research Letters 45, 748-757.

Sonoike K. (2011) Photoinhibition of Photosystem I. Physiologia Plantarum 142, 5664.

Soukupová J., Cséfalvay L., Urban O., Košvancová M., Marek M., Rascher U. \& Nedbal L. (2008) Annual variation of the steady-state chlorophyll fluorescence emission of evergreen plants in temperate zone. Functional Plant Biology 35, 63-76.

Springer K.R., Wang R. \& Gamon J.A. (2017) Seasonal patterns of photosynthesis, fluorescence, and reflectance indices in boreal trees. Remote Sensing 9, 1-18.

Sun Y., Frankenberg C., Jung M., Joiner J., Guanter L., Köhler P. \& Magney T. (2018) Overview of Solar-Induced chlorophyll Fluorescence (SIF) from the Orbiting Carbon Observatory-2: Retrieval, cross-mission comparison, and global monitoring for GPP. Remote Sensing of Environment 209, 808-823.

Sun Y., Frankenberg C., Wood J.D., Schimel D.S., Jung M., Guanter L., ... Yuen K. (2017) OCO-2 advances photosynthesis observation from space via solarinduced chlorophyll fluorescence. Science 358.

Thum T., Zaehle S., Köhler P., Aalto T., Aurela M., Guanter L., ... Markkanen T. (2017) Modelling sun-induced fluorescence and photosynthesis with a land surface model at local and regional scales in northern Europe. Biogeosciences 14, 1969-1987. 
van der Tol C., Berry J.A., Campbell P.K.E. \& Rascher U. (2014) Models of fluorescence and photosynthesis for interpreting measurements of solar-induced chlorophyll fluorescence. Journal of Geophysical Research: Biogeosciences $119,2312-2327$.

Verhoeven A. (2014) Sustained energy dissipation in winter evergreens. New Phytologist 201, 57-65.

Verrelst J., Rivera J.P., van der Tol C., Magnani F., Mohammed G. \& Moreno J. (2015) Global sensitivity analysis of the SCOPE model: What drives simulated canopy-leaving sun-induced fluorescence? Remote Sensing of Environment 166, 8-21.

Verrelst J., van der Tol C., Magnani F., Sabater N., Rivera J.P., Mohammed G. \& Moreno J. (2016) Evaluating the predictive power of sun-induced chlorophyll fluorescence to estimate net photosynthesis of vegetation canopies: a SCOPE modeling study. Remote Sensing of Environment 176, 139-151.

Walther S., Voigt M., Thum T., Gonsamo A., Zhang Y., Kohler P., ... Guanter L. (2016) Satellite chlorophyll fluorescence measurements reveal large-scale decoupling of photosynthesis and greenness dynamics in boreal evergreen forests. Global Change Biology 22, 2979-2996.

Wellburn A.R. (1994) Spectral determination of chlorophylls a and b, as well as total carotenoids, using various solvents with spectrophotometers of different resolution. Journal of Plant Physiology 144, 307-313.

Wieneke S., Burkart A., Cendrero-Mateo M.P., Julitta T., Rossini M., Schickling A., ... Rascher U. (2018) Linking photosynthesis and sun-induced fluorescence at sub-daily to seasonal scales. Remote Sensing of Environment 219, 247-258. 
Van Wittenberghe S., Alonso L., Verrelst J., Moreno J. \& Samson R. (2015)

Bidirectional sun-induced chlorophyll fluorescence emission is influenced by leaf structure and light scattering properties - A bottom-up approach. Remote Sensing of Environment 158, 169-179.

Wong C.Y.S. \& Gamon J.A. (2015) The photochemical reflectance index provides an optical indicator of spring photosynthetic activation in evergreen conifers. New Phytologist 206, 196-208.

Yang P. \& van der Tol C. (2018) Linking canopy scattering of far-red sun-induced chlorophyll fluorescence with reflectance. Remote Sensing of Environment 209, 456-467.

Yang P., van der Tol C., Verhoef W., Damm A., Schickling A., Kraska T., ... Rascher U. (2018) Using reflectance to explain vegetation biochemical and structural effects on sun-induced chlorophyll fluorescence. Remote Sensing of Environment.

Zarco-Tejada P.J., Catalina A., González M.R. \& Martín P. (2013) Relationships between net photosynthesis and steady-state chlorophyll fluorescence retrieved from airborne hyperspectral imagery. Remote Sensing of Environment 136, $247-258$.

Zarco-Tejada P.J., González-Dugo M. V. \& Fereres E. (2016) Seasonal stability of chlorophyll fluorescence quantified from airborne hyperspectral imagery as an indicator of net photosynthesis in the context of precision agriculture. Remote Sensing of Environment 179, 89-103.

Zarter C.R., Adams W.W., Ebbert V., Cuthbertson D.J., Adamska I. \& DemmigAdams B. (2006a) Winter down-regulation of intrinsic photosynthetic capacity 
coupled with up-regulation of Elip-like proteins and persistent energy dissipation in a subalpine forest. New Phytologist 172, 272-282.

Zarter C.R., Demmig-Adams B., Ebbert V., Adamska I. \& Adams W.W. (2006b) Photosynthetic capacity and light harvesting efficiency during the winter-tospring transition in subalpine conifers. New Phytologist 172, 283-292.

Zhang Y., Guanter L., Joiner J., Song L. \& Guan K. (2018) Spatially-explicit monitoring of crop photosynthetic capacity through the use of space-based chlorophyll fluorescence data. Remote Sensing of Environment 210, 362-374.

Zuromski L.M., Bowling D.R., Köhler P., Frankenberg C., Goulden M.L., Blanken P.D. \& Lin J.C. (2018) Solar-induced fluorescence detects interannual variation in gross primary production of coniferous forests in the western United States. Geophysical Research Letters 45, 7184-7193. 


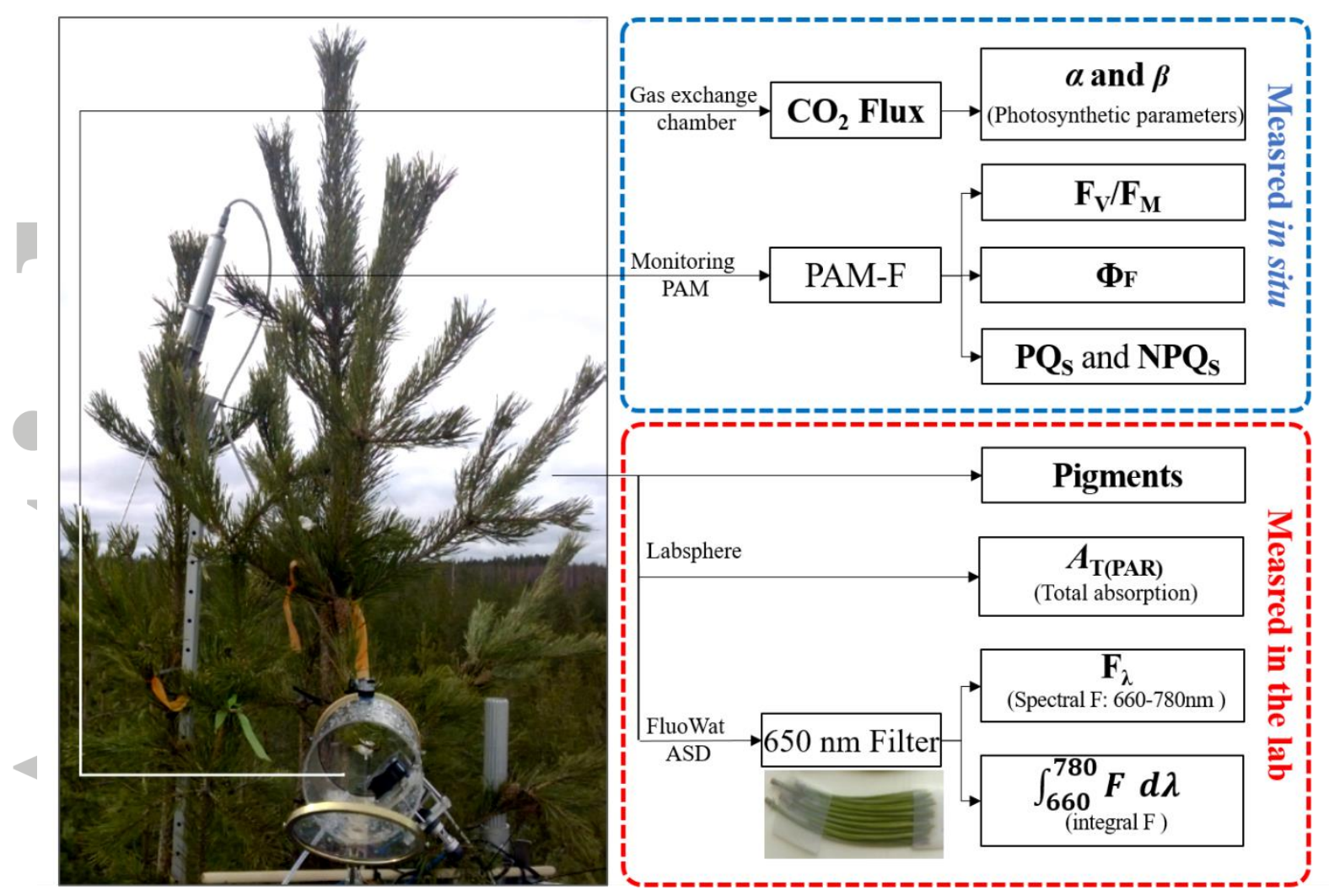

Fig. 1. Measurement rationale during the spring recovery of 2015 in Pinus sylvestris. 

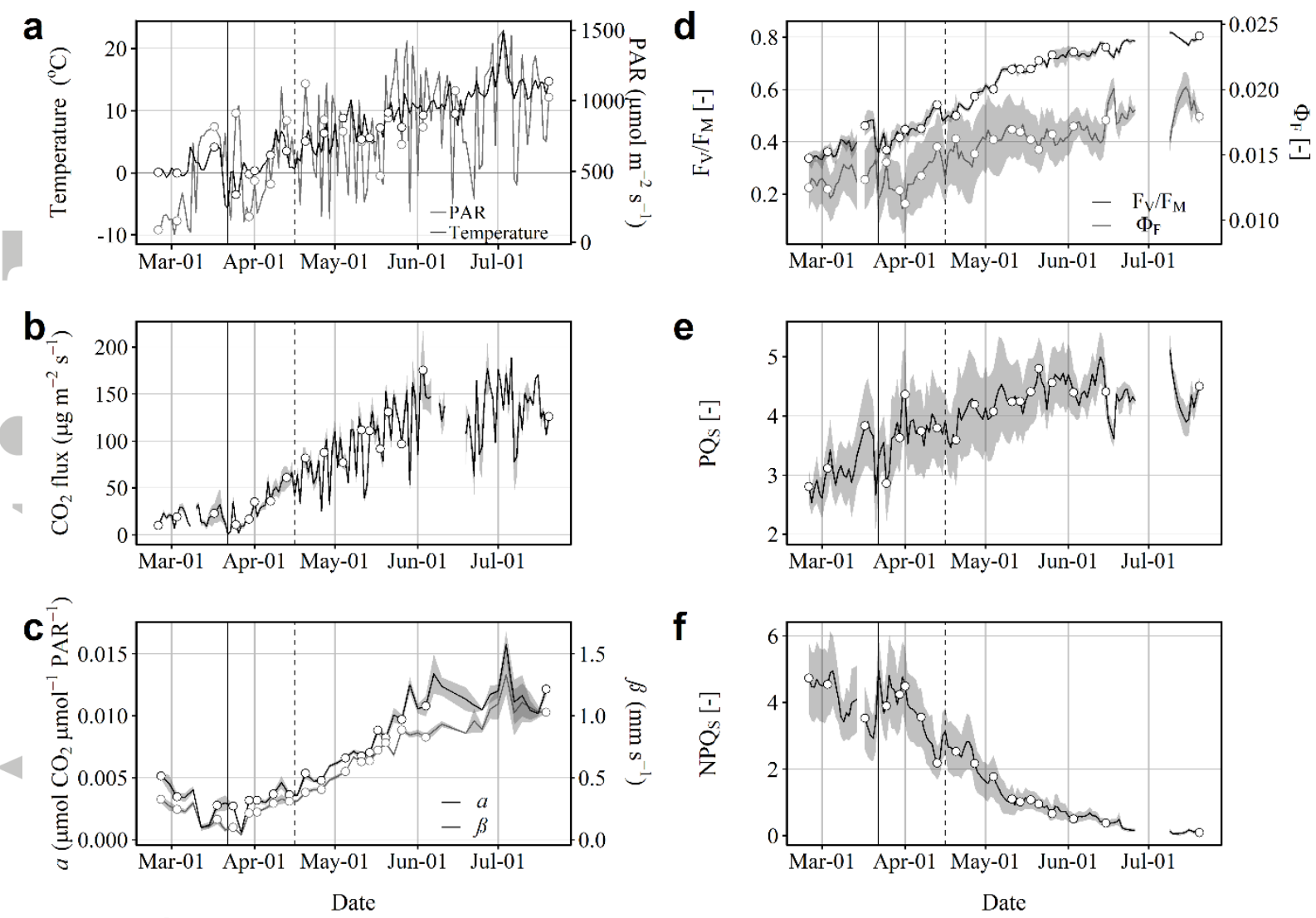

Fig. 2. Seasonal variation of meteorological and photosynthetic parameters. 

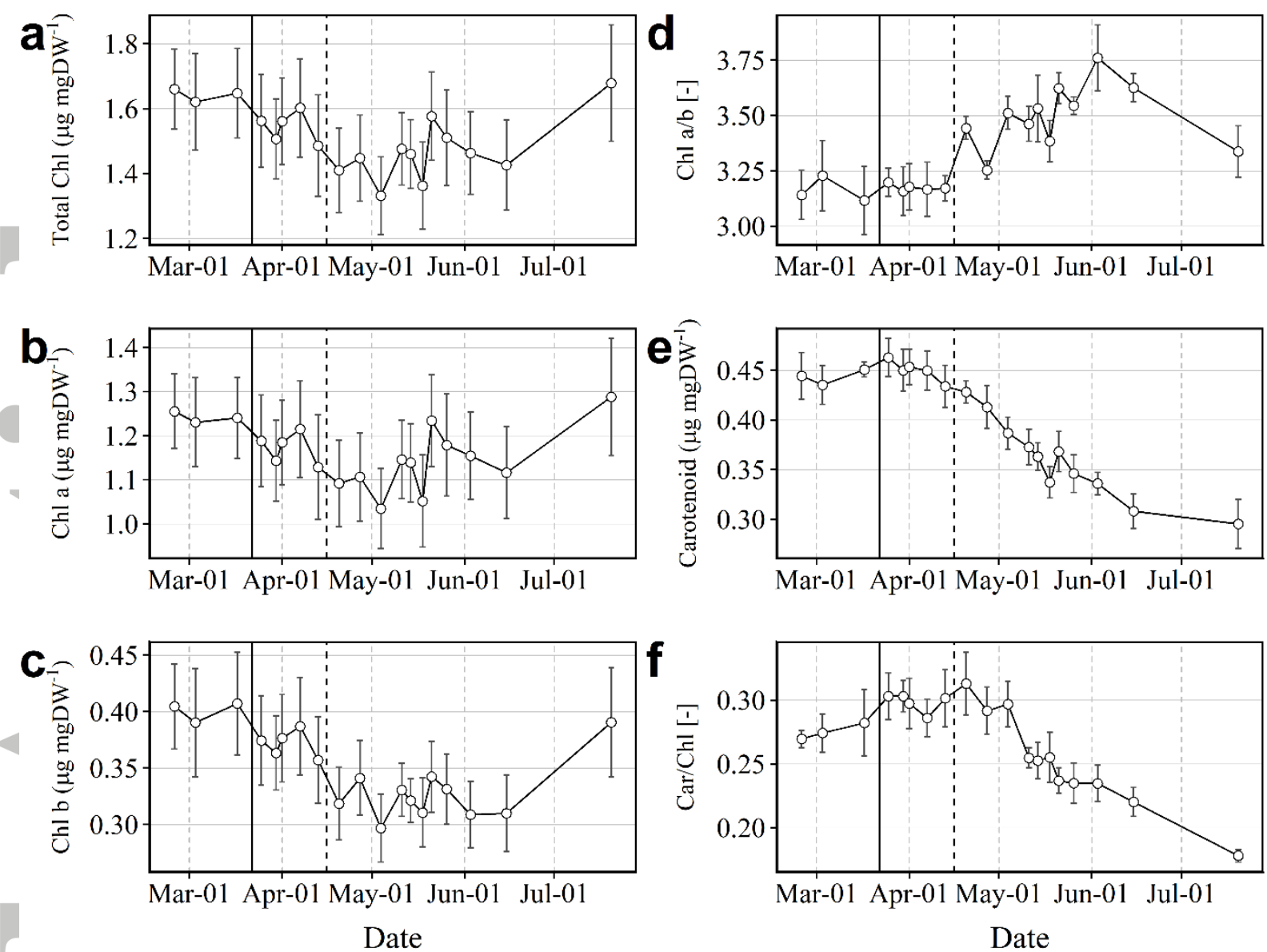

Date

Fig. 3. Seasonal variation of foliar pigment content. 

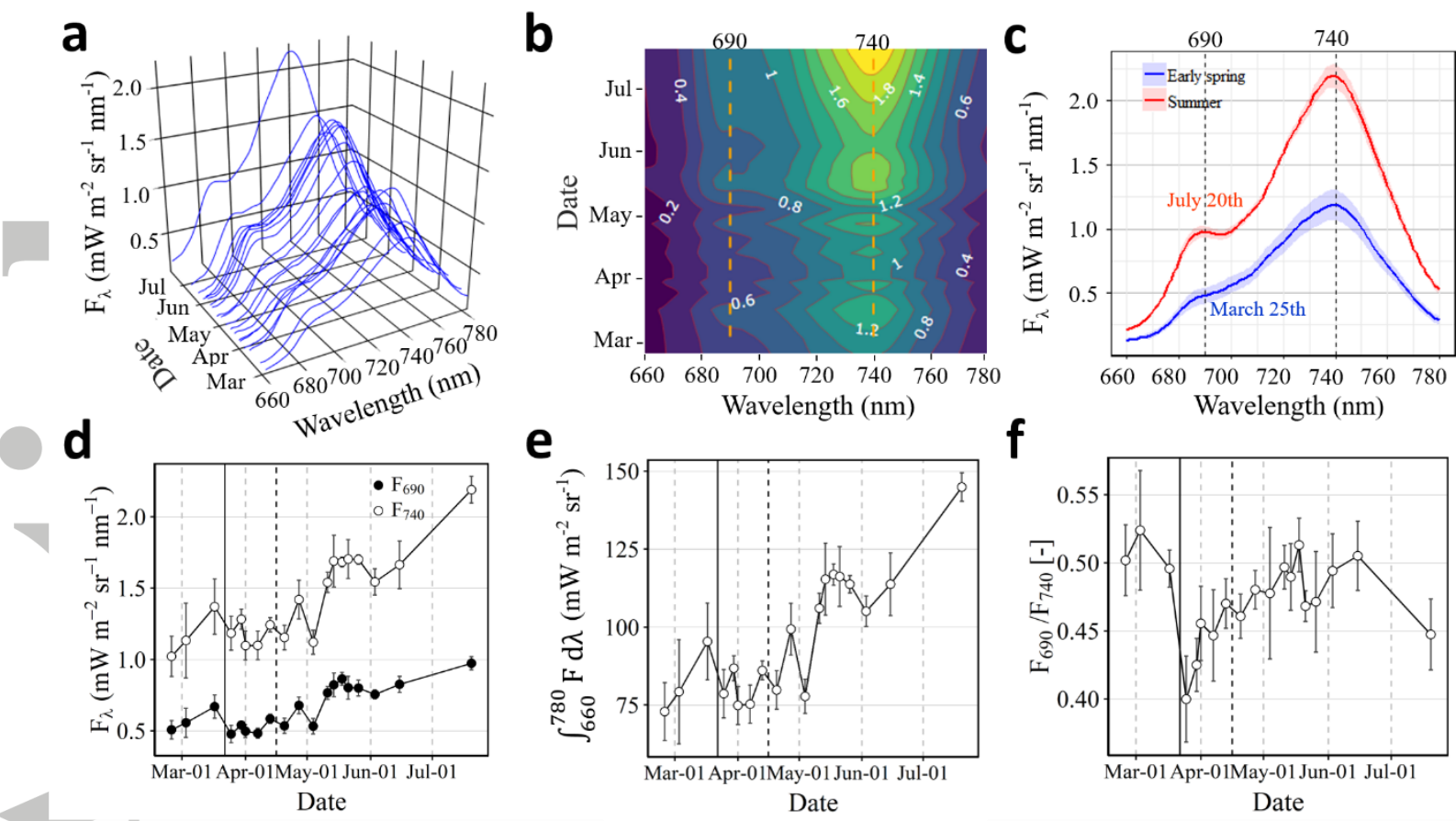

Fig. 4. Seasonal variation in spectral chlorophyll fluorescence (ChIF).

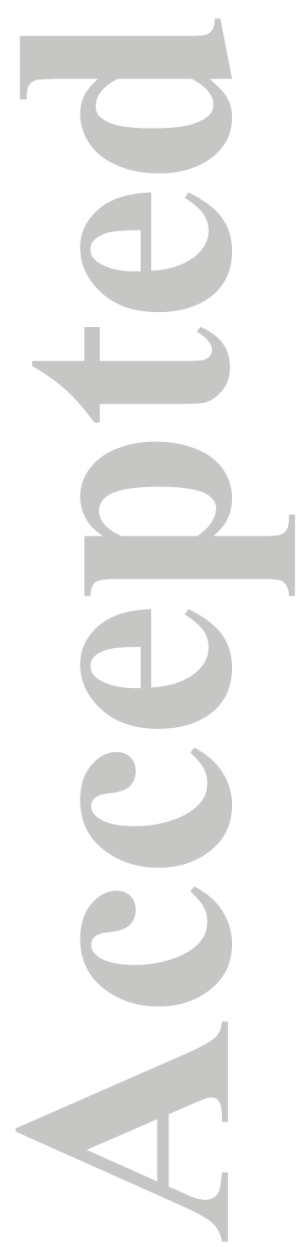



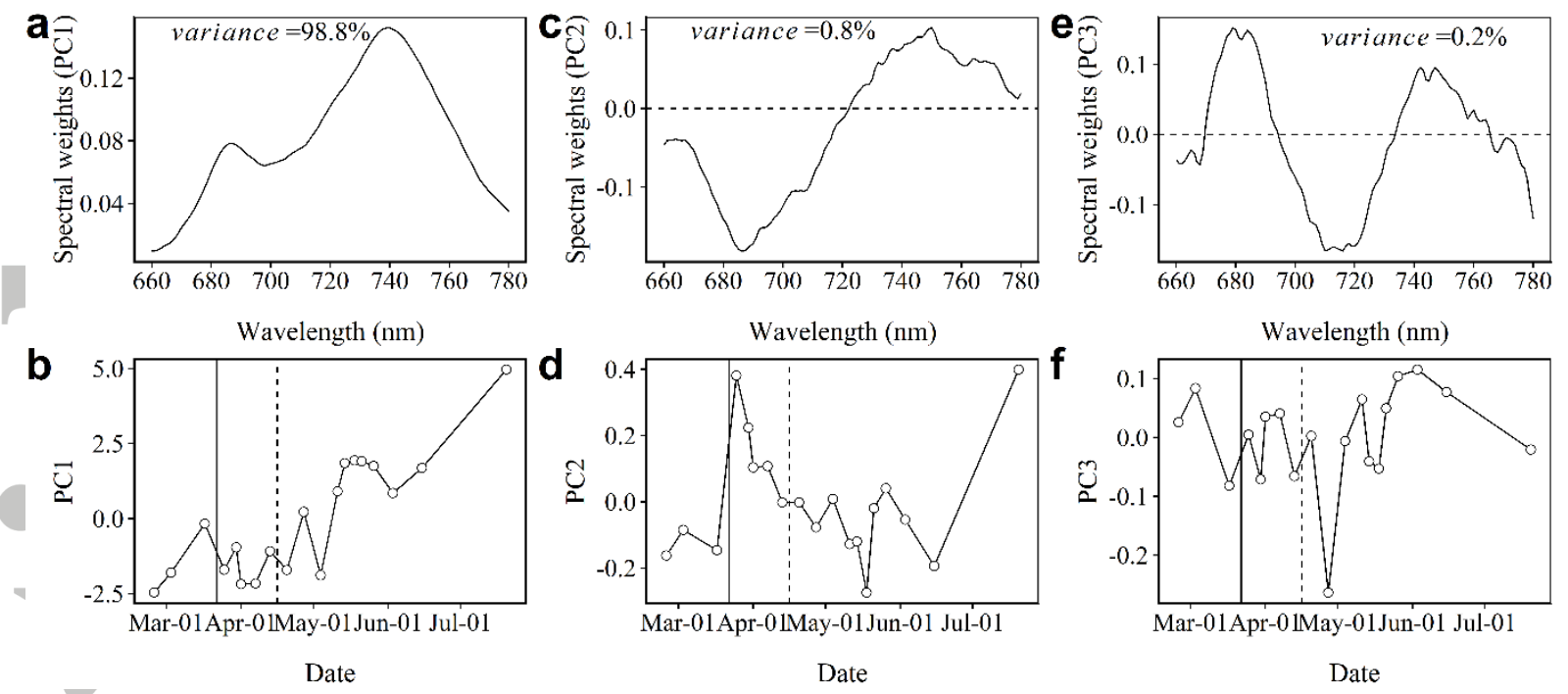

Fig. 5. Principal component analysis (PCA) for spectral chlorophyll fluorescence. 


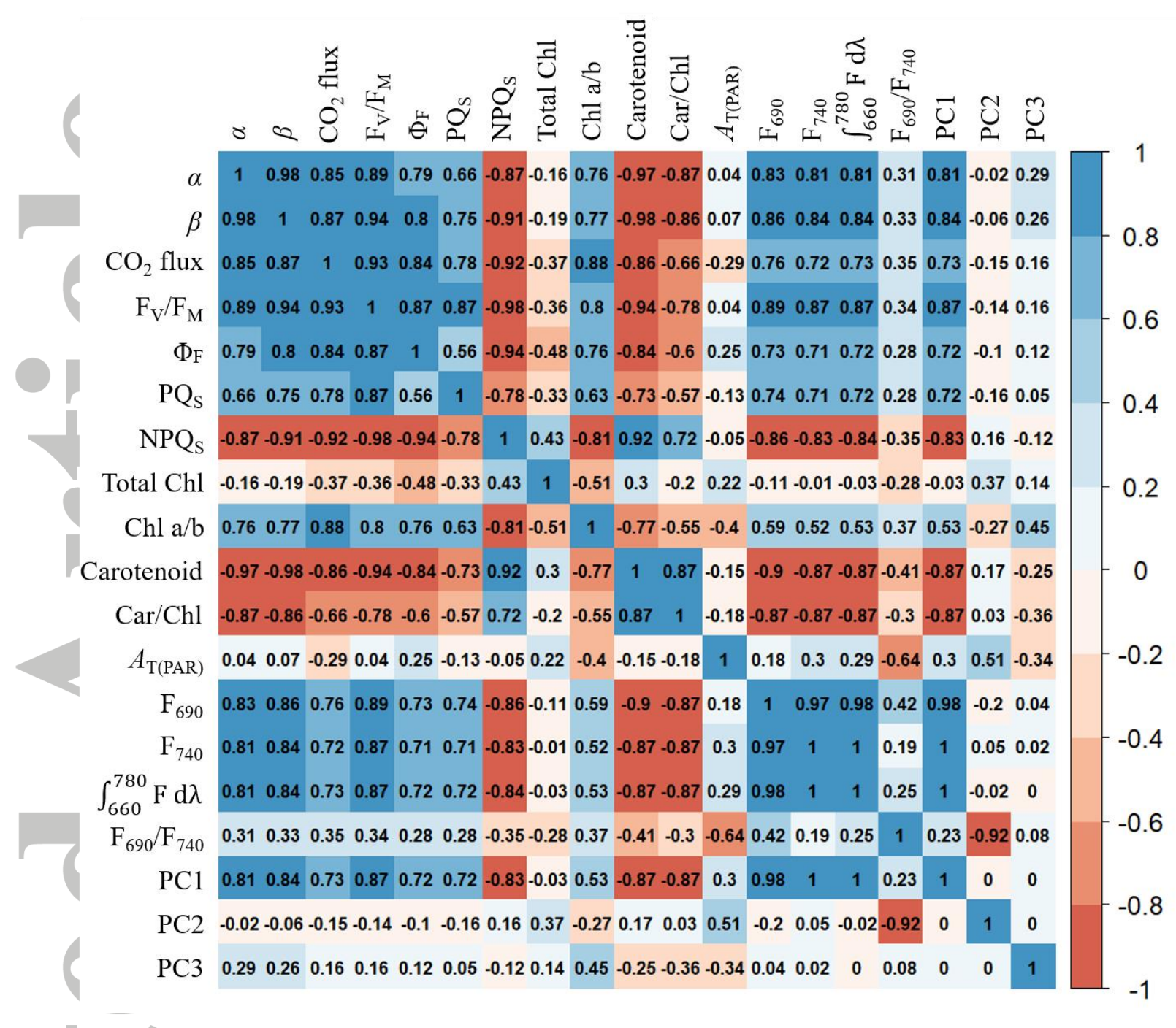

Fig. 6. Pearson correlation ( $r$ ) matrix between key study variables.

This article is protected by copyright. All rights reserved. 
a

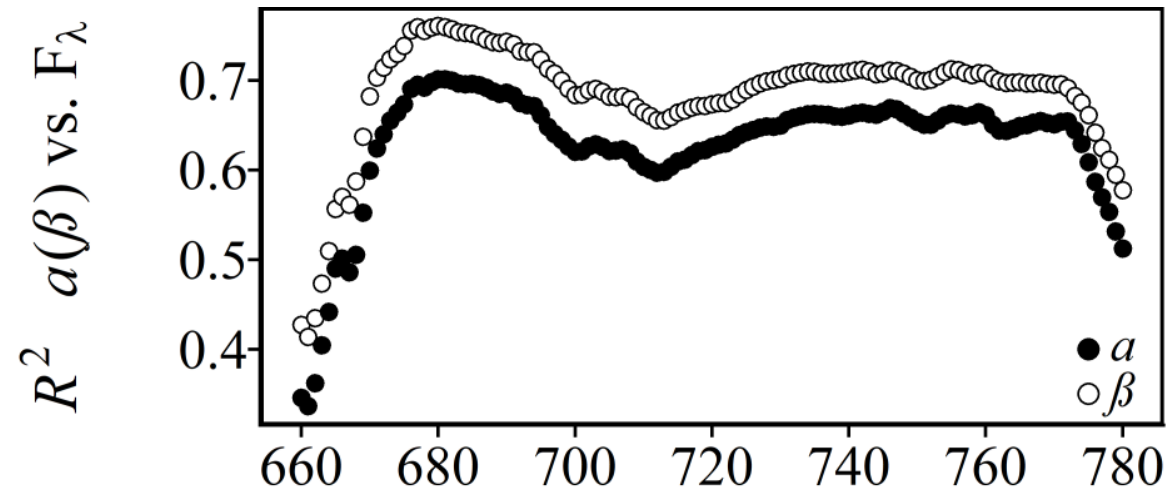

b

$1^{2}$
$\dot{n}$
0
0
0
$\frac{2}{5}$
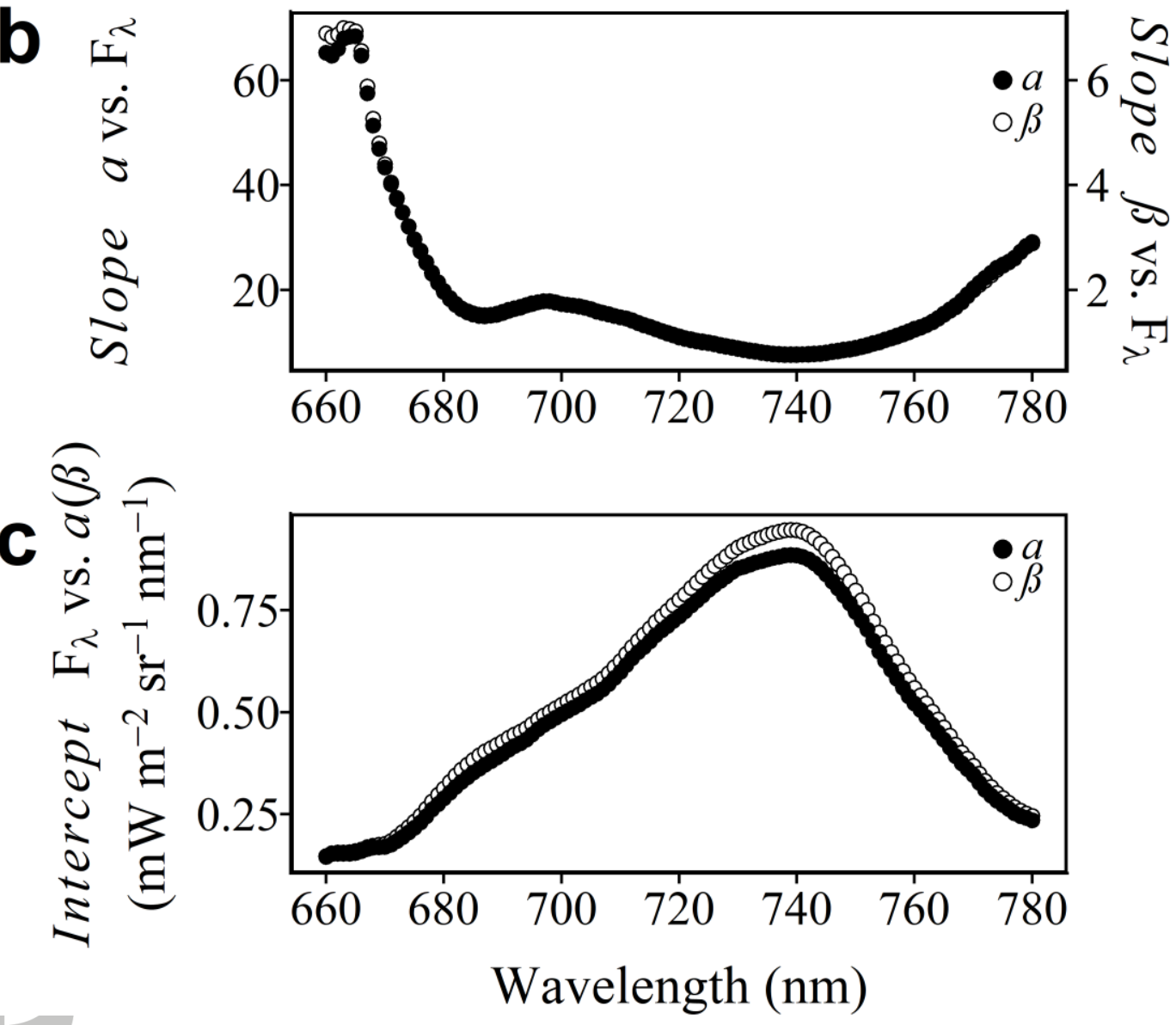

Fig.7. The linear regression between individual spectral fluorescence from 660 to 780 $\mathrm{nm}\left(\mathrm{F}_{\lambda}\right)$ and photosynthetic parameters $(\alpha$ and $\beta)$. 